\title{
Various Approaches to Forward and Inverse Wide-Angle Seismic Modelling Tested on Data from DOBRE-4 Experiment
}

\author{
Tomasz JANIK ${ }^{1}$, Piotr ŚRODA ${ }^{1}$, Wojciech CZUBA ${ }^{1}$, \\ and Dmytro LYSYNCHUK ${ }^{2}$
}

${ }^{1}$ Institute of Geophysics, Polish Academy of Sciences, Warsaw, Poland; e-mail: janik@igf.edu.pl

${ }^{2}$ Institute of Geophysics, National Academy of Sciences of Ukraine, Kiev, Ukraine

\begin{abstract}
The interpretation of seismic refraction and wide angle reflection data usually involves the creation of a velocity model based on an inverse or forward modelling of the travel times of crustal and mantle phases using the ray theory approach. The modelling codes differ in terms of model parameterization, data used for modelling, regularization of the result, etc. It is helpful to know the capabilities, advantages and limitations of the code used compared to others.

This work compares some popular 2D seismic modelling codes using the dataset collected along the seismic wide-angle profile DOBRE-4, where quite peculiar/uncommon reflected phases were observed in the wavefield.

The $\sim 505 \mathrm{~km}$ long profile was realized in southern Ukraine in 2009 , using 13 shot points and 230 recording stations. Double $\mathrm{P}_{\mathrm{M}} \mathrm{P}$ phases with a different reduced time (7.5-11 s) and a different apparent velocity, intersecting each other, are observed in the seismic wavefield. This is the most striking feature of the data. They are interpreted as reflections from strongly dipping Moho segments with an opposite dip. Two steps were used for the modelling. In the previous work by Starostenko et al. (2013), the trial-and-error forward model based on refracted
\end{abstract}

Ownership: Institute of Geophysics, Polish Academy of Sciences;

(C) 2016 Janik et al. This is an open access article distributed under the Creative Commons Attribution-NonCommercial-NoDerivs license,

http://creativecommons.org/licenses/by-nc-nd/3.0/. 
and reflected phases (SEIS83 code) was published. The interesting feature is the high-amplitude $(8-17 \mathrm{~km})$ variability of the Moho depth in the form of downward and upward bends. This model is compared with results from other seismic inversion methods: the first arrivals tomography package FAST based on first arrivals; the JIVE3D code, which can also use later refracted arrivals and reflections; and the forward and inversion code RAYINVR using both refracted and reflected phases. Modelling with all the codes tested showed substantial variability of the Moho depth along the DOBRE-4 profile. However, SEIS83 and RAYINVR packages seem to give the most coincident results.

Key words: seismic modelling, Moho boundary, ray tracing, tomography inversion.

\section{INTRODUCTION}

The interpretation of data from seismic refraction and wide angle reflection profiles usually involves the creation of the P-wave velocity model based on forward or automated inverse modelling of the travel times of observed crustal and mantle phases. Such a model is sometimes considered as a first step, followed for example by synthetic seismogram calculations using the full-waveform method, or as a final result. The codes used for velocity modelling are usually based on ray theory and allow for tracing of seismic rays through the medium with a given velocity distribution and for calculation of corresponding travel times from sources to receivers. The velocity model is sought by minimizing the difference between observed and calculated travel times. Two approaches for such a modelling exist. In the first one, the forward problem is solved for a given initial model by calculation of ray paths and travel times; then, the inverse problem is solved by manual trial-anderror modifications of the model, seeking to improve the fit of the calculated and observed travel times. Both steps are applied repetitively. It is possible to verify and, if needed, correct the phase identification during this procedure. The second approach is a mostly automated procedure. An initial model is updated in a number of iterative steps to minimize the misfit of observed and calculated travel times, e.g., in the simplest case according to the regularized least squares method.

During the last few decades, an inverse (tomographic) modelling mostly replaced a forward approach as a faster and more effective tool for the determination of the seismic velocity distribution, due to several drawbacks of the latter method. A manual, trial-and-error process of attempting to fit the data for several shotpoints simultaneously can be very tedious, difficult and time-consuming, compared to inverse methods. Also, as the sequence of model modifications depends on the interpreter's decisions, it introduces some subjectivity into the final solution. The result of the inverse modelling 
is also subjective to some extent - as in any type of travel time modelling, it depends on a subjective process of picking the seismic phases. Moreover, it depends on arbitrary settings of the inversion procedure (e.g., choice of the grid spacing, values of the smoothing/regularization weights, etc.) but once these parameters are set, given the input data, the calculations are easy to repeat, e.g., in order to independently verify the result, which is not the case for the forward approach. Also, a systematic evaluation of the model resolution and uncertainty is problematic for the forward approach.

However, the advantage of the forward modelling is the possibility to continuously control the correctness of the interpretation of seismic data (identification of the travel times of given seismic phase as a refraction or reflection from a particular layer/discontinuity). At each stage, the interpreter can verify the identification of picked seismic phases. For example, difficulties in fitting some particular seismic phase by a model consistently fitting all the remaining data can help to decide if a "suspect" phase actually comes from an "in-line", 2D structure (e.g., from a local high-velocity body) and should be incorporated into a 2D model, or if it originates as a side reflection or diffraction from some local structure, and thus should not be used for the calculation of a 2D model. This helps to avoid significant model errors, bias or artefacts that could be introduced by the modelling of some (initially) wrongly identified phases, whose nature at first glance may not be obvious. The proper identification of seismic phases used for modelling was stressed by Zelt (1999) who wrote that "A model developed by the analysis of wideangle travel time data is only as good as the picks".

The DOBRE-4 WARR profile (Starostenko et al. 2013) was realized in southern Ukraine in 2009. The experiment was aimed at investigating the structure of the crust and uppermost mantle at the southwestern corner of the East European Craton (the East European Platform and Ukrainian Shield), at its transition into the Trans-European Suture Zone (TESZ). The location of the DOBRE-4 profile is shown in Fig. 1. It extends (Fig. 2) from the Lower Prut High in the SW through the South Ukrainian Homocline to the Ukrainian Shield. The profile crosses the Precambrian East European Craton and its younger SW part, the Scythian Platform. Its margin is a major tectonic boundary, the Teisseyre-Tornquist Zone (Guterch et al. 1986), representing contact with younger, Palaeozoic and Alpine units.

The seismic model along the profile and its geological and tectonic interpretation is presented by Starostenko et al. (2013). The unusual features observed in the seismic wavefield are triplications of the Moho reflections. They are visible in several record sections as superimposed branches of the $\mathrm{P}_{\mathrm{M}} \mathrm{P}$ phase with a different apparent velocity, intersecting each other (Figs. 3a and b). Such recordings, interpreted as reflections from a steeply undulating Moho discontinuity, are rather uncommon and present a valuable 


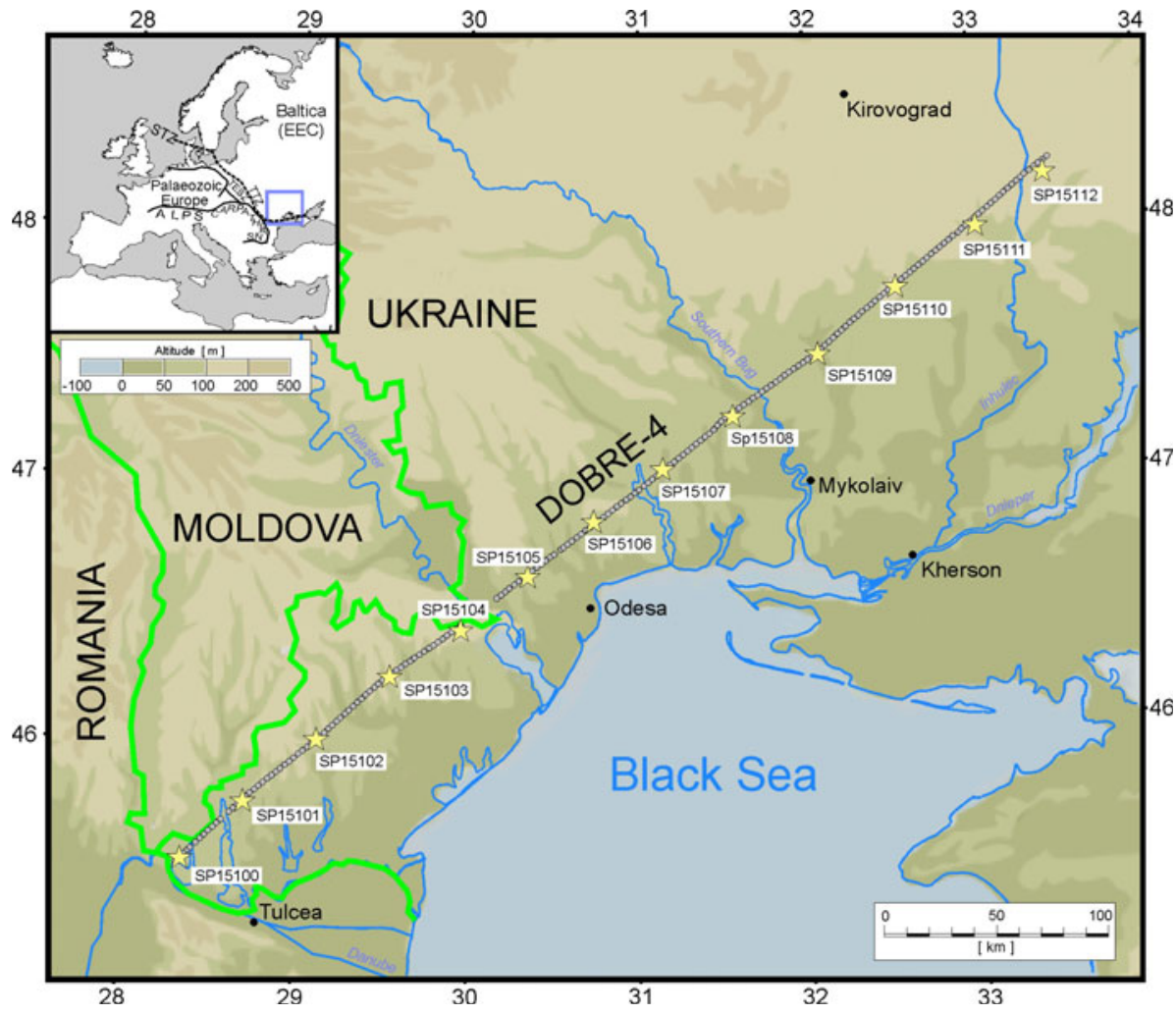

Fig. 1. Location of the DOBRE-4 profile. The yellow stars represent shot points, grey dots show the recording stations of the experiment. The inset map indicates the location of the study area in Europe. EEC - East European Craton, STZ Sorgenfrei-Tornquist Zone, TTZ - Teisseyre-Tornquist Zone.

material to test the various approaches of $2 \mathrm{D}$ wide-angle modelling (this unusual phenomenon was previously seen on other DSS profile in Ukrainian Shield and interpreted as $\mathrm{P}_{\mathrm{M}} \mathrm{P}$ triplication in paper by Grad and Tripolsky (1995)). Therefore, this paper is an attempt to test how such a complex Moho structure can be resolved, depending on the phases used for modelling $\left(\mathrm{P}_{\mathrm{M}} \mathrm{P}\right.$ only, $\mathrm{P}_{\mathrm{n}}$ only, $\left.\mathrm{P}_{\mathrm{M}} \mathrm{P}+\mathrm{P}_{\mathrm{n}}\right)$ but also depending on the modelling approach and model parameterization.

To compare the published model obtained by modelling using the SEIS83 package (Červený and Pšenčík 1984), we have chosen, from the many codes available (e.g., also Korenaga et al. 2000, Koulakov 2009, Rawlinson and Urvoy 2006), several well known and popular codes: FAST by Zelt and Barton (1998) - a code for tomographic inversion of travel times corresponding to refracted waves, JIVE3D by Hobro (1999) and Hobro et al. 


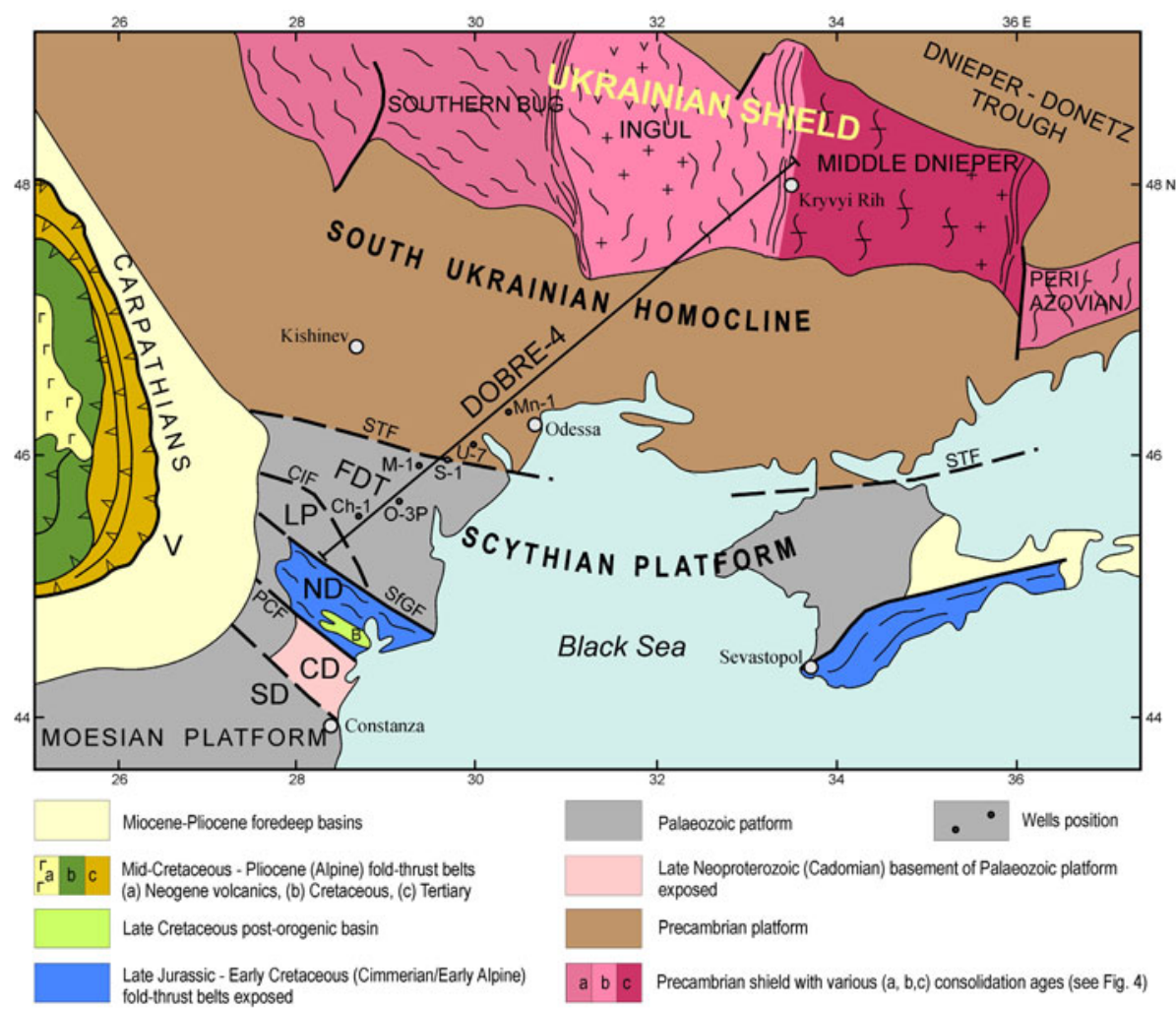

Fig. 2. Tectonic setting of profile DOBRE-4. Abbreviations: B - Babadag Basin, CD - Central Dobrudja, CIF - Cahul-Ismail Fault, FDT - Fore-Dobrudja Trough, LP - Lower Prut High, ND - North Dobrudja, PCF - Peceneaga-Camena Fault, SD - Southern Dobrudja, SfGF - Sfantu Gheorghe Fault, STF - Scytho-Turanian Fault, V - Vrancea. The deep boreholes: Ch1 - Chervonoarmeyskaya-1, O-3P Orekhovskaya-3P, M-1 - Mirnopolskaya-1, S-1 - Saratskaya-1, U-7 - Uspenovskaya-7, Mn-1 - Mirnenskaya-1.

(2003) - a joint refraction and reflection travel time tomography code, and RAYINVR by Zelt and Smith (1992) - code for travel time inversion with a small number of model parameters related by a priori functionals for relatively simple final models. In general, available codes differ in terms of velocity model parameterization (equidistant grid or user-defined arbitrary grid, adaptive grid, single grid or separate grids for predefined layers separated by velocity discontinuities), the travel time data used for modelling (first arrivals only or all observed arrivals, including reflections), smoothing/ regularization of the result. This is by no means a representative selection of various modelling methods, but anyway it allows us to check the result of 
(a)
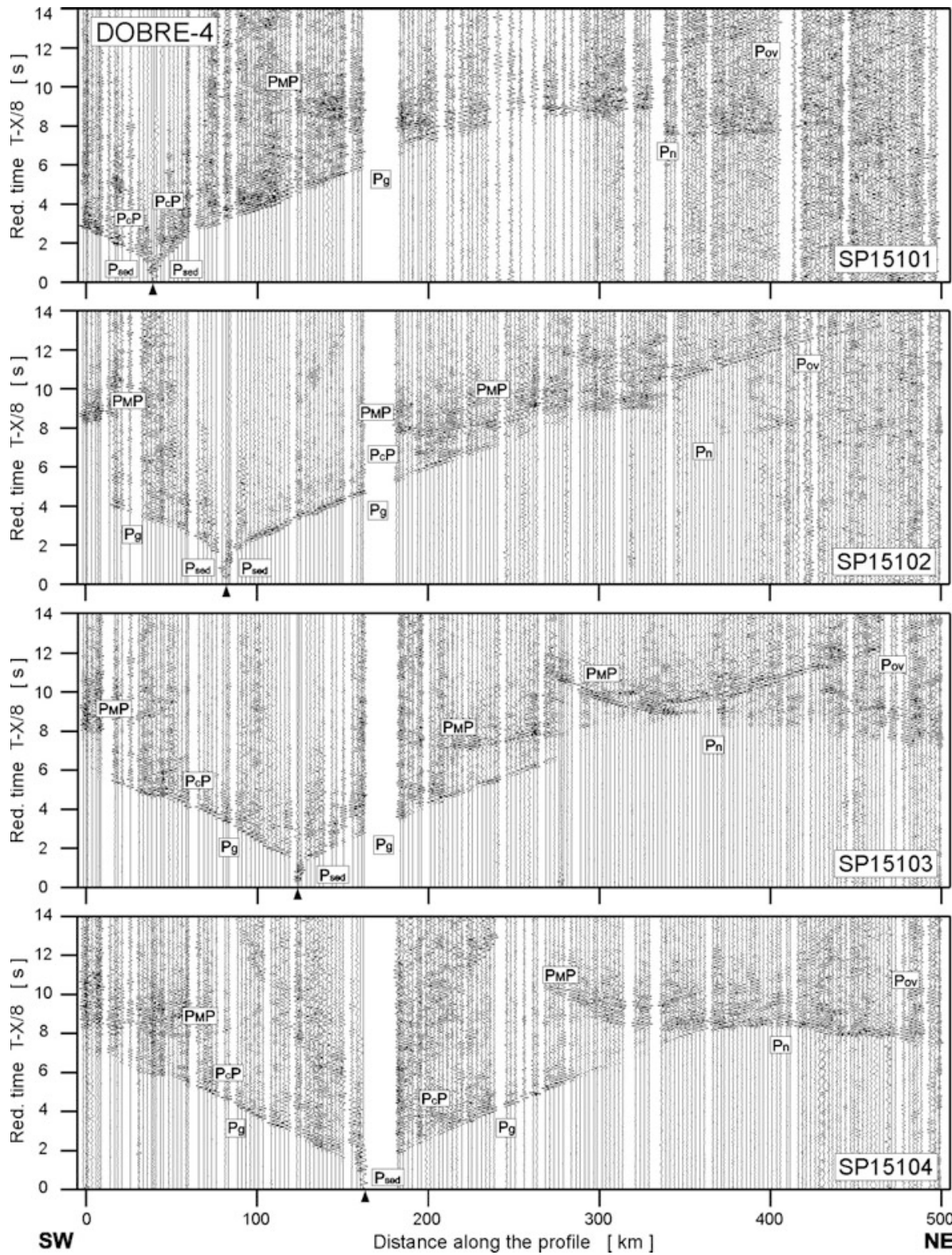

Fig. 3. Caption on next page.

modelling for a few basically different approaches - forward or inverse modelling, usage of reflected $\left(\mathrm{P}_{\mathrm{M}} \mathrm{P}\right)$ or refracted $\left(\mathrm{P}_{\mathrm{n}}\right)$ waves, representation of the velocity model as a single layer or as multiple layers, parameterization 
(b)
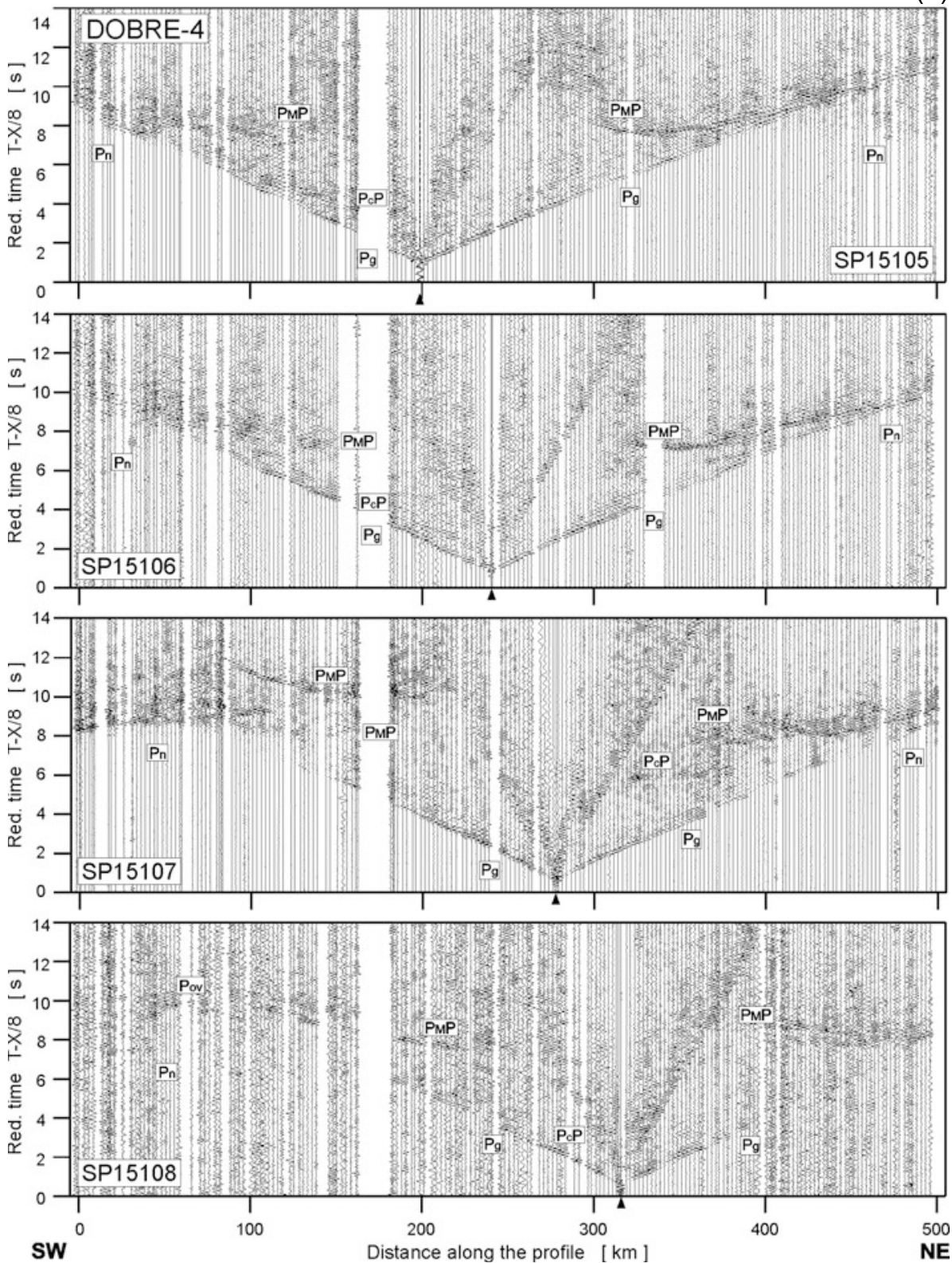

Fig. 3. Caption on next page.

on dense, regular velocity grid versus a sparse, irregular grid. Recently, a comparison of computational possibilities and limitations of above mentioned codes was published by Malinowski (2013). 
(c)

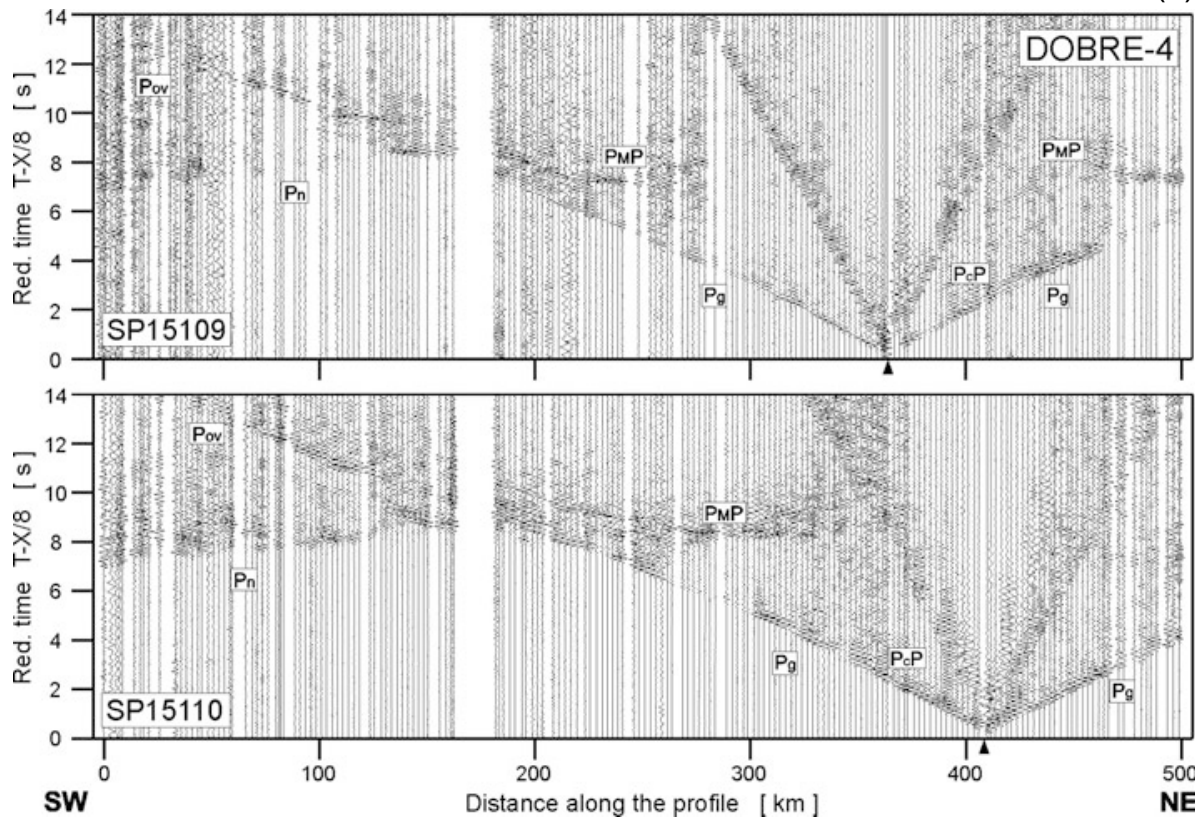

Fig. 3: (a)-(c) Example of trace-normalized, vertical-component seismic record sections for the P-wave (SP15101-SP15110), filtered by the band-pass filter 2-12 Hz. Abbreviations: $\mathrm{P}_{\mathrm{g}}$ - seismic refractions from the upper and middle crystalline crust, $\mathrm{P}_{\text {ov }}-$ overcritical crustal phases, $\mathrm{P}_{\mathrm{c}} \mathrm{P}-$ reflections from the middle crust discontinuities, $\mathrm{P}_{\mathrm{M}} \mathrm{P}$ - reflected waves from the Moho boundary, $\mathrm{P}_{\mathrm{n}}-$ refractions from the subMoho upper mantle. The reduction velocity is $8.0 \mathrm{~km} / \mathrm{s}$.

\section{DATA}

The DOBRE-4 profile is $\sim 505 \mathrm{~km}$ long. The field acquisition included 13 shot points (SP), every $30-50 \mathrm{~km}$ and 230 recording stations, every $2.5 \mathrm{~km}$.

The seismic sections recorded along the profile are of good quality. A detailed description of the recorded wavefield was presented by Starostenko et al. (2013). The seismic record sections are presented in Fig. 3. The record sections show a complex character of the wavefield, particularly the phases reflected from the Moho discontinuity, reflecting its complex topography along the profile.

\subsection{P-wave refracted and reflected arrivals}

The first P-wave arrivals represent the refracted waves from the upper crustal sedimentary layers $\left(\mathrm{P}_{\text {sed }}\right)$, the upper/middle crystalline crust $\left(\mathrm{P}_{\mathrm{g}}\right)$, and the phases from the upper mantle $\left(\mathrm{P}_{\mathrm{n}}\right)$. The $\mathrm{P}_{\text {sed }}$ phases, representing the re- 
fractions in the sedimentary sequences, are observed in the southern part of the profile. At larger distances $(10-200 \mathrm{~km})$, the $P_{g}$ phase is observed. The waves propagating in the mantle $\left(\mathrm{P}_{\mathrm{n}}\right)$ are observed on several shot points for the offset range of about $200-400 \mathrm{~km}$. They represent refractions below the Moho and, possibly, reflections from the mantle discontinuities and scattered/diffracted waves. The latter phases may appear to be in "first arrivals" if the real first arrival phase - the Moho refraction - is not visible in the seismic section due to its low amplitude.

Reflected phases at 7.5-11 s reduced travel time and 100-250 km offset range are the most striking feature observed in the DOBRE-4 dataset. They are very coherent and with extremely high amplitudes. In the sections at both ends of the profile, they represent a typical $\mathrm{P}_{\mathrm{M}} \mathrm{P}$ phase (reflection from the Moho boundary). On the other sections, we often observe two phases - with a slow and fast apparent velocity, intersecting each other (e.g., SP15103, Fig. 3) or arriving at a different reduced time (e.g., SP15107 with a shallower Moho reflection at $\sim 8 \mathrm{~s}$ reduced time and a deeper one at $\sim 10 \mathrm{~s}$ reduced time).

Travel time picking uncertainties, estimated based on the pulse width and on the signal-to-noise ratio and used for modelling with all tested codes, are $0.1 \mathrm{~s}$ for the refracted waves $\left(\mathrm{P}_{\mathrm{sed}}, \mathrm{P}_{\mathrm{g}}, \mathrm{P}_{\mathrm{ov}}, \mathrm{P}_{\mathrm{n}}\right)$ and $0.2 \mathrm{~s}$ for Moho reflections $\left(\mathrm{P}_{\mathrm{M}} \mathrm{P}\right) . \mathrm{P}_{\mathrm{ov}}$ are phases of later refracted crustal arrivals ("overcritical").

\section{SEISMIC MODELLING}

\subsection{Forward modelling with SEIS83}

The trial-and-error forward modelling was done (Starostenko et al. 2013) using the SEIS83 package (Červený and Pšenčík 1984) with the graphical interface MODEL (Komminaho 1998) and ZPLOT (Zelt 1994). The code uses the shooting method (tracing a ray starting at the source for given initial direction by solving the ray (eikonal) equation) for calculation of the ray paths, travel times, and synthetic seismograms in the high-frequency approximation. The model consists of layers with seismic velocities parameterized on a non-equidistant, user-defined rectangular grid and interpolated by bicubic splines. Velocity discontinuities are allowed between the individual layers. An initial model of the velocity distribution in the uppermost crust presented in Fig. 4 was used in the modelling.

Resolving the velocity distribution of the upper crustal sedimentary layers along the profile is important for the further modelling of the deeper structure of the crust. The geological and geophysical data, boreholes and nearby CDP studies were used to prepare a cross section and the starting model of the upper crust (Fig. 4a). 


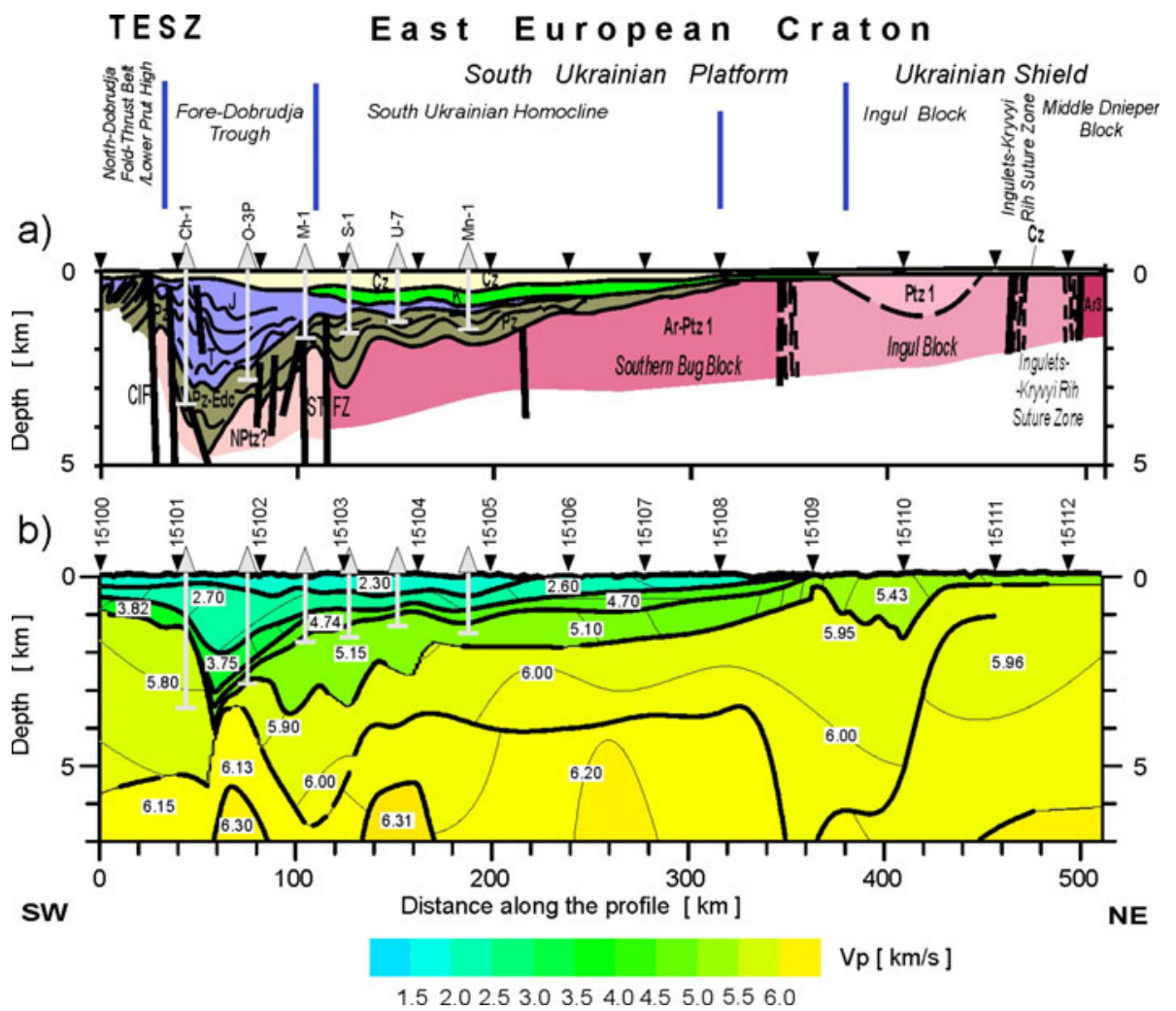

Fig. 4: (a) A simplified geological cross section based on seismic investigations, outcrop geology data, and six $1.5 \mathrm{~km}$ to $3.5 \mathrm{~km}$ deep boreholes located within $5.6 \mathrm{~km}$ of the profile, in the southwestern part (abbreviations are as in Fig. 2). Age assignments: Ar - Archaean, Ptz - Proterozoic, Edc - Ediacaran, Pz - Palaeozoic, T - Triassic, J - Jurassic, $\mathrm{K}$ - Cretaceous, $\mathrm{Cz}$ - Cenozoic. Major faults: CIF - Cahul-Ismail Fault, STFZ - Scytho-Turanian Fault Zone. These data were used as a basis for building a starting model (for details see text); (b) The final 2D model (SEIS83) of the seismic P-wave velocity in the sedimentary cover; vertical exaggeration is $\sim 19.3: 1$. The position of large-scale crustal blocks is indicated. The arrows show positions of shot points. The grey triangles mark location of boreholes.

Fig. 5. 2D model of seismic P-wave velocity in the crust and upper mantle derived by forward ray tracing modelling using the SEIS83 package: (a) Travel time residuals; (b) Diagrams showing theoretical (black) and observed travel times (green); and (c) Ray coverage. Yellow lines - fragments of discontinuities constrained by reflected phases. The red points plotted along the interfaces mark the bottoming points of the modelled reflected phases (every third point is plotted) and their density is a measure of the positioning accuracy of the reflectors. DWS - derivative weight sum. The reduction velocity is $8 \mathrm{~km} / \mathrm{s}$; (d) The model is the same as that published by Starostenko et al. (2013). Respective calculated travel times differ by no more than 


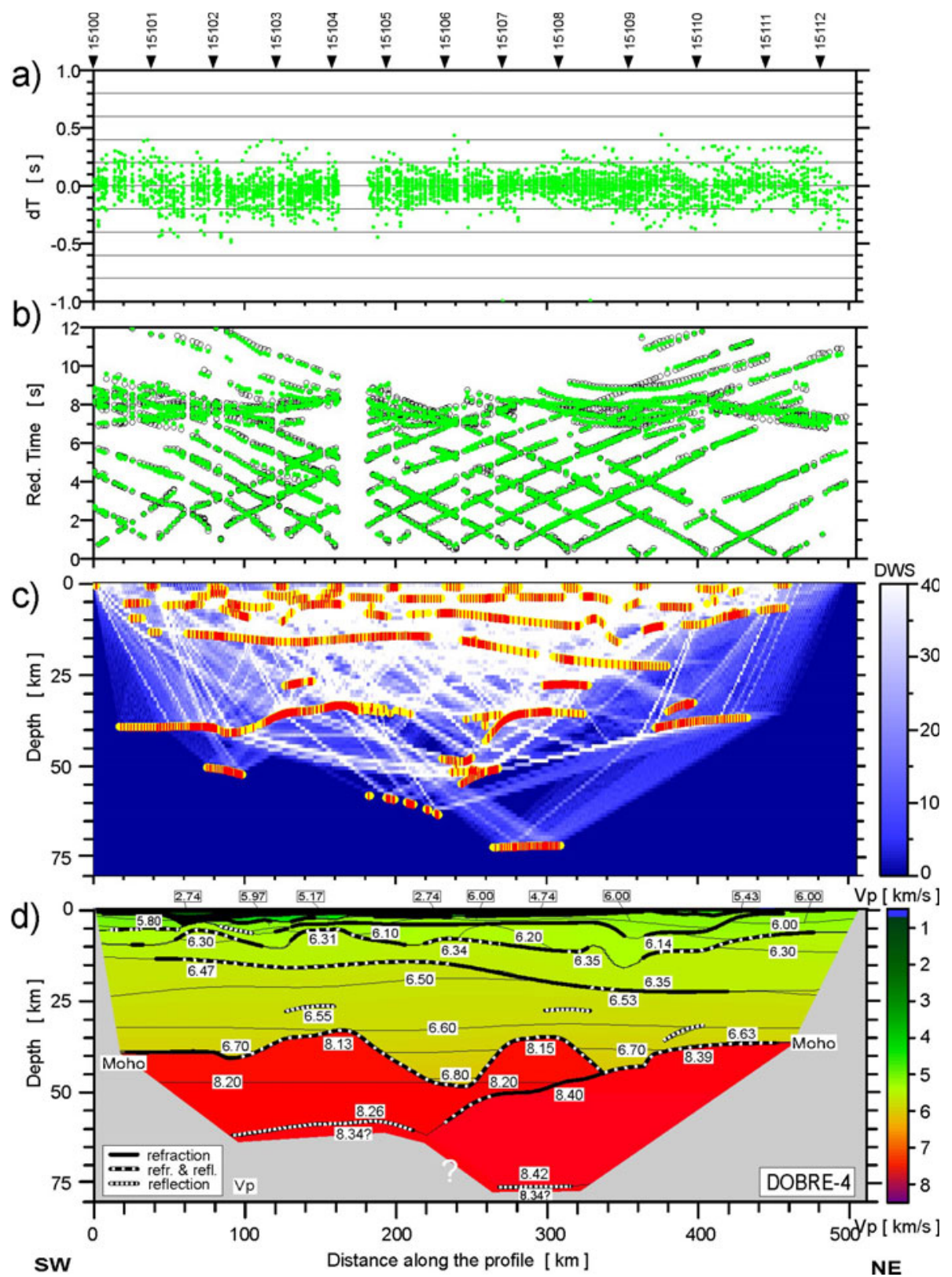

$0.1 \mathrm{~s}$ from the previous one. Those parts of the first order discontinuities that have been constrained by reflected or/and refracted arrivals of $\mathrm{P}$ waves are marked by thick lines. The thin lines represent velocity isolines with values in $\mathrm{km} / \mathrm{s}$ shown in white boxes. The vertical exaggeration is $\sim 2.4: 1$. 
The solution was sought in a succession of attempts to improve the data fit by modifying model parameters. Based on travel time misfit, the model was manually modified in order to enhance the data fit. The modelling also involved the calculation of synthetic seismograms. Amplitudes of synthetic and observed data were then qualitatively compared. This provided better constraints on the velocity gradients and contrasts at the discontinuities.

The high quality of the analysed data allowed for constructing a velocity model (Fig. 5) that fits the observed (experimental) travel times for both refracted and reflected waves with good accuracy. An example is shown in Fig. 13 in the paper by Starostenko et al. (2013). Diagrams showing theoretical and observed travel times for all the phases along the profile, ray coverage and travel time residuals from forward modelling are shown in Fig. 5. The RMS (and $\left.\chi^{2}\right)$ values are $0.36 \mathrm{~s}\left(\chi^{2}=13\right)$ for $\mathrm{P}_{\text {sed }}, 0.16 \mathrm{~s}\left(\chi^{2}=2.6\right)$ for the $\mathrm{P}_{\mathrm{g}}$ and $\mathrm{P}_{\mathrm{ov}}$ phases (waves refracted in the crust), $0.17 \mathrm{~s}\left(\chi^{2}=0.72\right)$ for $\mathrm{P}_{\mathrm{M}} \mathrm{P}$, and $0.31 \mathrm{~s}\left(\chi^{2}=9.6\right)$ for Moho refractions ( $P_{n}$ phases). The overall RMS value for 3880 picks is $0.37 \mathrm{~s}\left(\chi^{2}=3.9\right)$. The abilities of this modelling package are summarized in Table 1.

Table 1

Comparison of the abilities of modelling software packages used in this study

\begin{tabular}{|c|c|c|c|c|c|c|}
\hline $\begin{array}{l}\text { Package } \\
\text { (modelling } \\
\text { method) }\end{array}$ & $\begin{array}{c}\text { Phases } \\
\text { possible } \\
\text { to use }\end{array}$ & $\begin{array}{c}\text { Phases } \\
\text { used }\end{array}$ & $\begin{array}{c}\text { P-wave } \\
\text { velocity } \\
\text { distribution }\end{array}$ & $\begin{array}{c}\text { Sedimentary } \\
\text { layer taken } \\
\text { into account }\end{array}$ & $\begin{array}{l}\text { Determination } \\
\text { of the crustal } \\
\text { and Moho } \\
\text { discontinuities }\end{array}$ & $\begin{array}{c}\text { Synthetic } \\
\text { seismograms }\end{array}$ \\
\hline $\begin{array}{l}\text { FAST } \\
\text { (tomographic } \\
\text { inversion) }\end{array}$ & $\begin{array}{c}\text { first } \\
\text { arrivals }\end{array}$ & $\begin{array}{l}\mathrm{P}_{\mathrm{g}}, \\
\mathrm{P}_{\mathrm{n}}\end{array}$ & $+(+)$ & - & - & - \\
\hline $\begin{array}{l}\text { JIVE3D } \\
\text { (tomographic } \\
\text { inversion) }\end{array}$ & all & $\begin{array}{l}\mathrm{P}_{\mathrm{g}} \\
\mathrm{P}_{\mathrm{M}} \mathrm{P} \\
\mathrm{P}_{\mathrm{n}} \\
\mathrm{P}_{\mathrm{ov}} \\
\end{array}$ & $+(+)$ & $+(-)$ & $\begin{array}{l}+(-) \\
+(+)\end{array}$ & - \\
\hline $\begin{array}{l}\text { RayInvr } \\
\text { (forward } \\
\text { and inverse } \\
\text { modelling) }\end{array}$ & all & $\begin{array}{l}\mathrm{P}_{\mathrm{g}} \\
\mathrm{P}_{\mathrm{M}} \mathrm{P} \\
\mathrm{P}_{\mathrm{n}}\end{array}$ & $+(+)$ & $+(+)$ & $\begin{array}{l}+(-) \\
+(+)\end{array}$ & $+(-)$ \\
\hline $\begin{array}{l}\text { SEIS83 } \\
\text { (forward } \\
\text { modelling) }\end{array}$ & all & $\begin{array}{l}\mathrm{P}_{\mathrm{g}} \\
\mathrm{P}_{\mathrm{c}} \mathrm{P} \\
\mathrm{P}_{\mathrm{M}} \mathrm{P} \\
\mathrm{P}_{\mathrm{n}} \\
\mathrm{P}_{\mathrm{ov}}\end{array}$ & $+(+)$ & $+(+)$ & $\begin{array}{l}+(+) \\
+(+)\end{array}$ & $+(+)$ \\
\hline
\end{tabular}

Notice: Marks in parentheses concern features actually used in this study. 

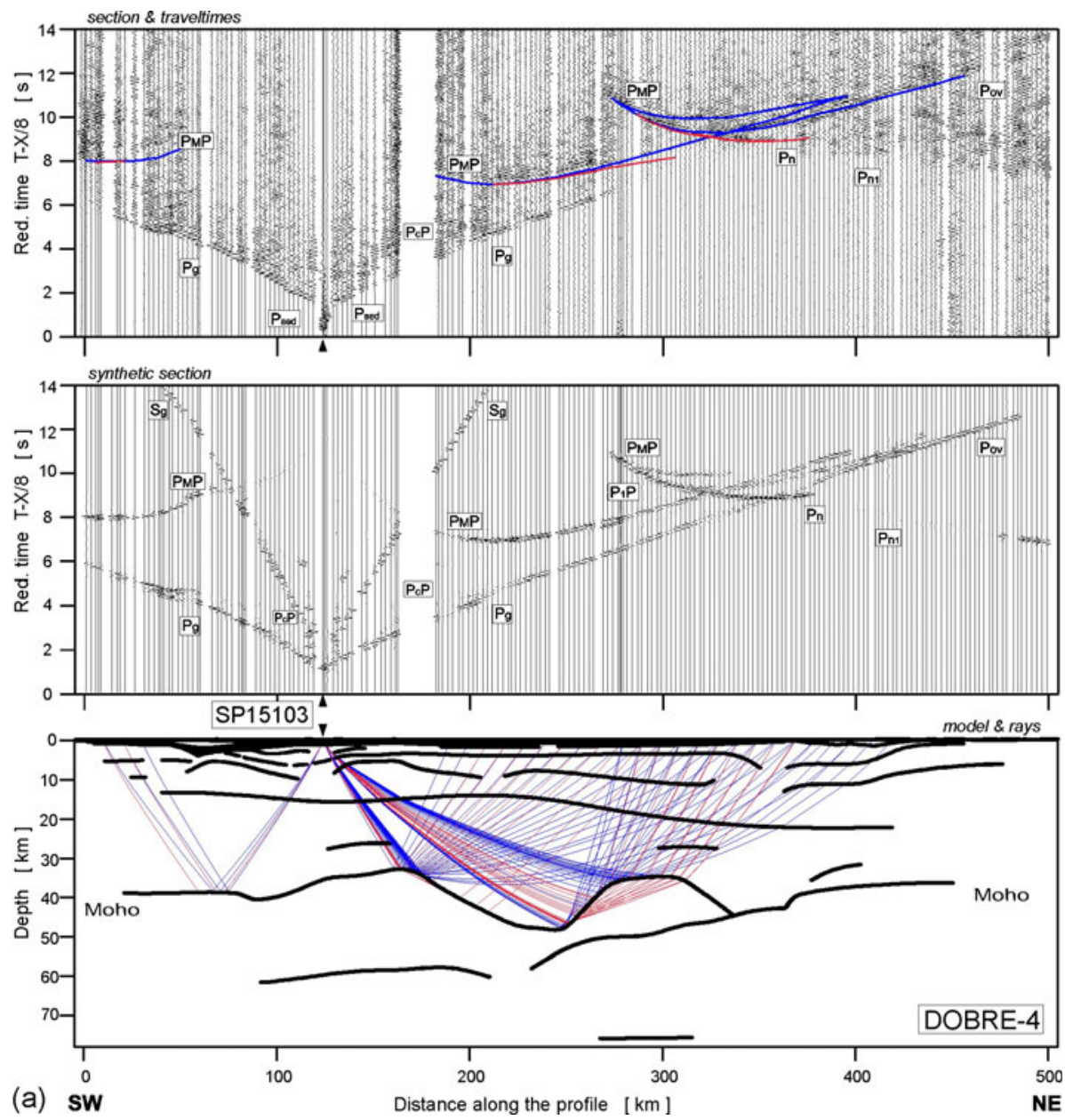

Fig. 6. Caption on next page.

The forward modelling showed that double arrivals observed on the record sections (Figs. 3a and b) represent the reflections from the oppositedipping segments of a strongly undulating Moho boundary (Starostenko et al. 2013). The fragments of the travel time curve with high apparent velocity were reflected by the Moho fragments dipping up with increasing offset, while those with slow velocity were reflected from the Moho segments dipping down. Together, this produces characteristic triplication of the travel time curve. Usually, these phases are of very good quality; therefore, in spite of their unusual character, they could be identified with a high confidence. Examples of modelling $\mathrm{P}_{\mathrm{M}} \mathrm{P}$ waves for shots 15103, 15105, 15107, and 15110 are presented in Fig. 6. 

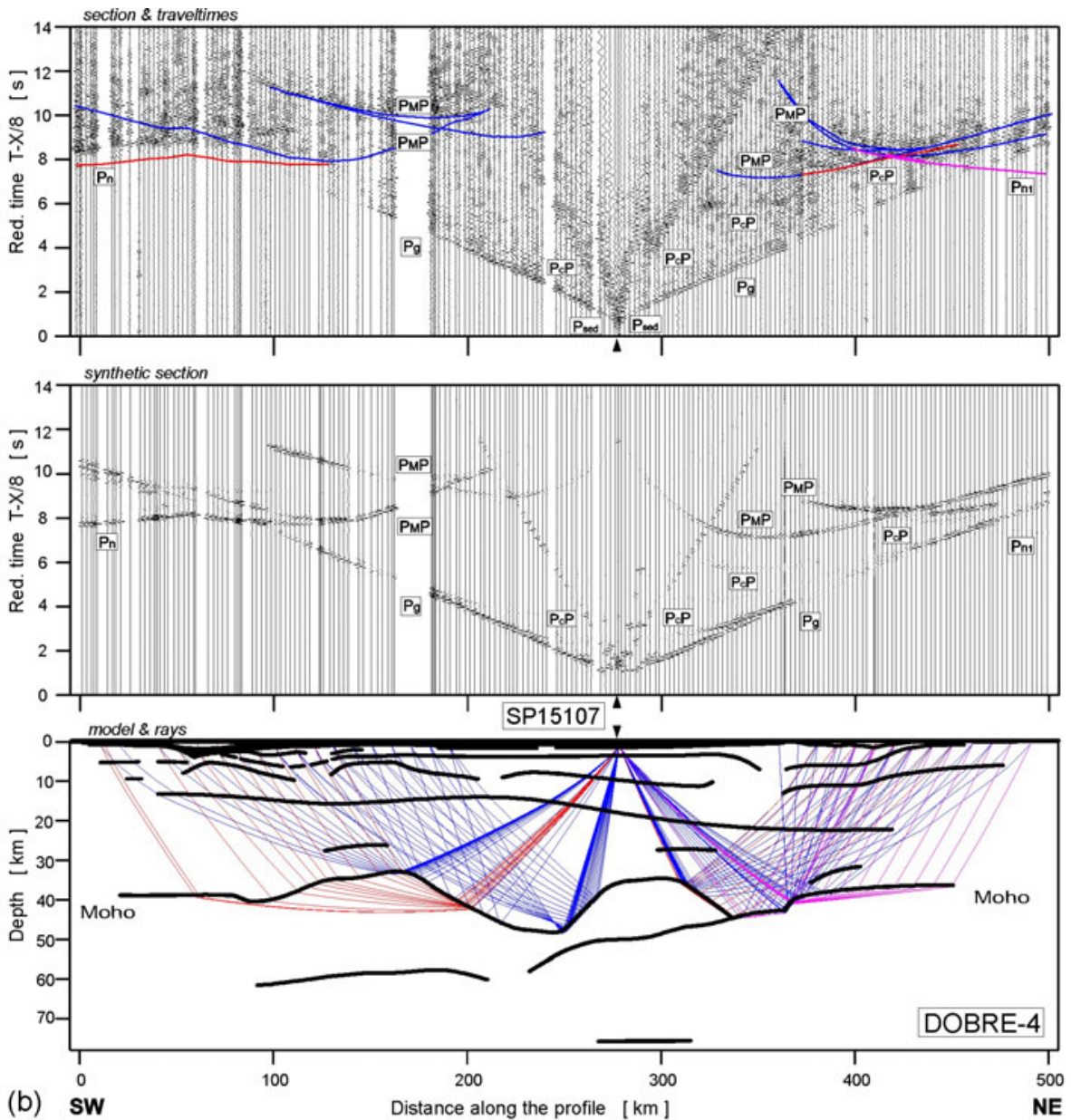

Fig. 6: (a)-(b). Examples of seismic modelling of the P-wave with selected theoretical travel times $\left(\mathrm{P}_{\mathrm{M}} \mathrm{P}\right.$ and $\mathrm{P}_{\mathrm{n}}$ - blue and red travel times, respectively) calculated using the SEIS83 ray tracing technique for SP15103 and SP15107, respectively. Seismic record sections (amplitude-normalized vertical component, the band-pass filter of 2-12 Hz, reduction velocity of $8.0 \mathrm{~km} / \mathrm{s}$ ). Synthetic seismograms (middle diagram) and the ray diagram of selected rays using the SEIS83 (bottom diagram). All examples were calculated for the model presented in Fig. 5d. $\mathrm{P}_{\mathrm{n} 1}$ - refraction in the higher velocity upper mantle. Other abbreviations are as in Fig. 3.

\subsection{Refraction travel time tomography with FAST}

We have used the First Arrival Seismic Tomography (FAST) program (Zelt and Barton 1998) to invert first arrivals of refracted $P_{\text {sed }}, P_{g}$, and $P_{n}$ phases. The velocity model is parameterized on a rectangular equidistant grid. FAST 
uses an eikonal solver in the forward step to produce travel times and ray paths for an initial velocity model. In the inverse step, regularized inversion based on LSQR variant of conjugate gradient technique is used to obtain velocity perturbations from the travel time residuals. The method allows the user to constrain the flatness and smoothness of the slowness perturbations. Velocity calculations are organized in iterative form in order to minimize the root mean square residual difference between the calculated and observed travel times. This procedure allows the nonlinear problem to be linearized and to solve the linear system in several iterations and is a common way to get the Earth's interior velocity based on travel times of the first seismic arrivals on some general information to build an initial model. Similarly to all travel time tomographic codes, the drawback of FAST is a smoothing of (potentially existing) velocity contrasts in the resulting model which is characteristic of all tomographic inversion methods. Any iterative inversion involves for the smoothing of results to ensure the stability of the whole process and also FAST uses the velocity parameterization on a continuous grid without the existence of velocity discontinuities representing geological boundaries or fault zones.

Another issue in case of most inversion methods is the influence of the initial model on the solution. The final model is strongly dependent on the initial one, and we were faced with this problem too. We have got very different resulting models for the number of initial ones, which may suggest that the data $\left(\mathrm{P}_{\mathrm{g}}\right.$ and $\mathrm{P}_{\mathrm{n}}$ phase alone) do not have good resolving capability. A formal criterion to stop the iterative inversion process is reaching $\chi^{2} \sim 1$ (meaning that differences between the observed and estimated travel times are comparable to data uncertainty, thus the data fit is satisfactory). In order to obtain a model with an acceptable fit and simplest velocity structure possible, a smoothing of the velocity field is usually applied.

However, in a number of cases, applying several inversion iterations, besides decreasing $\chi^{2}$, leads also to the appearance of small-scale velocity anomalies, which are most likely artefacts due to uneven and anisotropic ray coverage (directions of rays propagating trough given model cell are not distributed uniformly).

When working on this model, it was found that the occurrence of these artefacts for some acceptable $\chi^{2}$ (for instance less than 2) depends on the proximity of the initial and final model. In other words, it is easier to get the final model without obvious artefacts and satisfactory fit when the initial model already shows a reasonable travel time fit to the data. Thus, it is important to properly select the initial model. Figure 7 represents the velocity distribution calculated using the FAST package. The model size was $500 \times 72 \mathrm{~km}$ and grid spacing was $1 \times 1 \mathrm{~km}$ for the forward calculations of the rays and $5 \times 2 \mathrm{~km}$ for inverse computations. The code allows for taking 


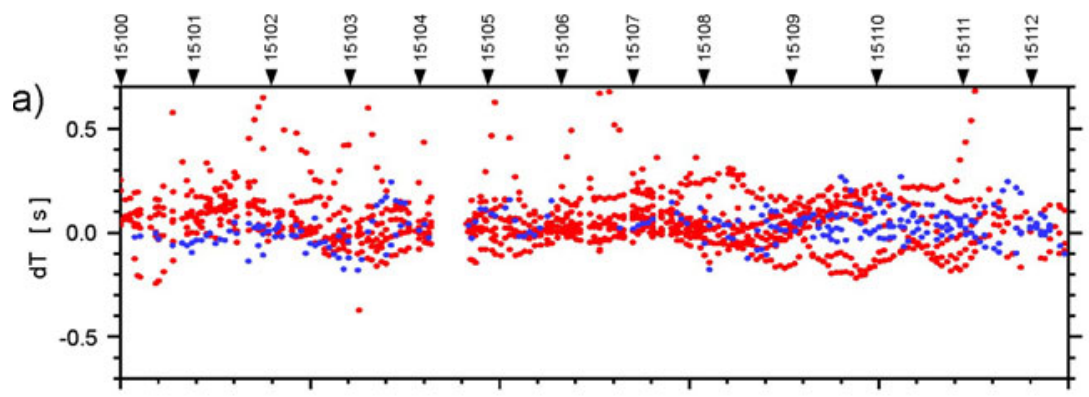

b)
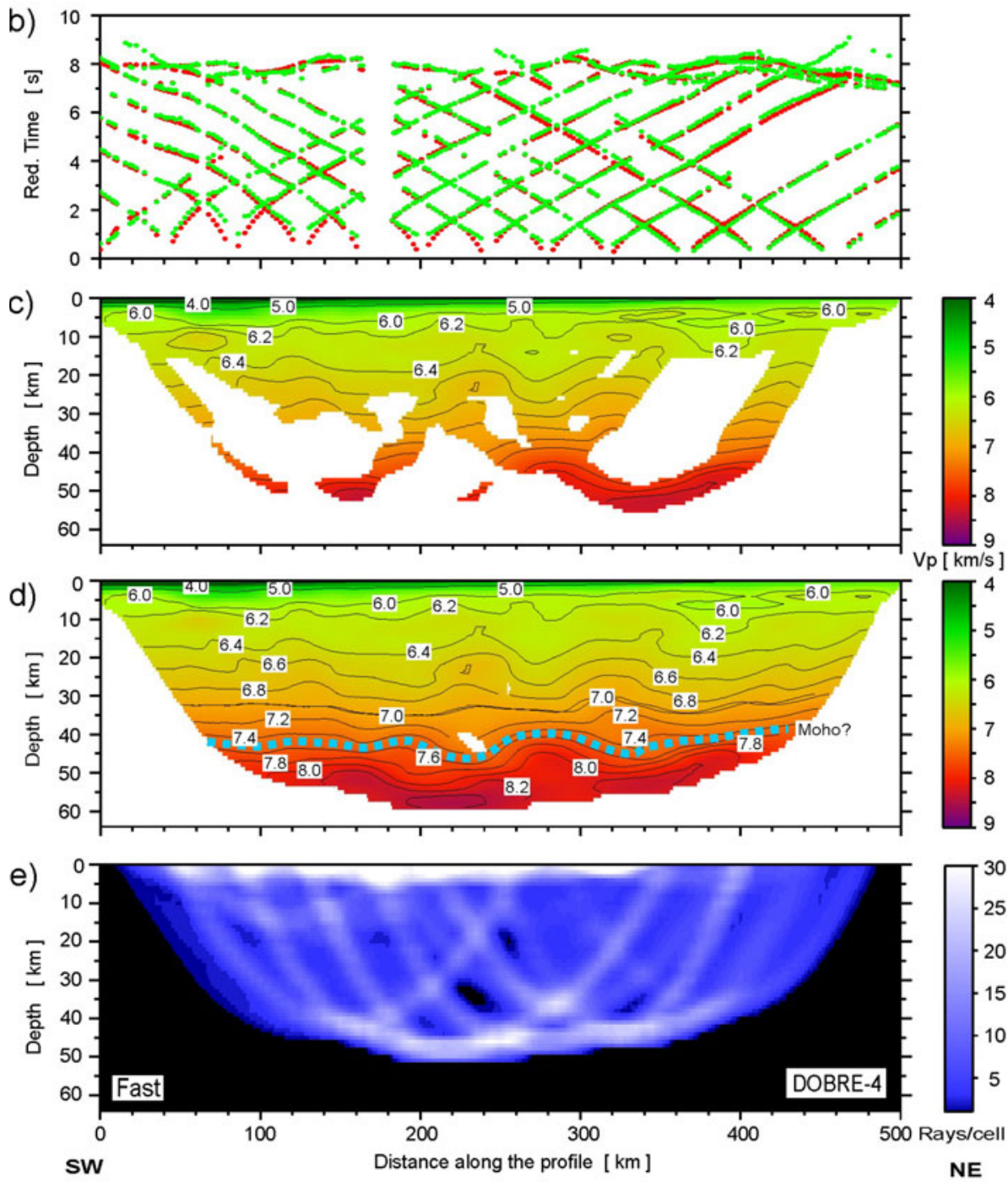
the surface topography into account by positioning the source and receiver at their true depth. However, as the elevation along the DOBRE-4 profile did not exceed $160 \mathrm{~m}$, a constant elevation $(0 \mathrm{~m}$ a.s.1.) of sources and receiver was assumed for the modelling. The data set included $1139 \mathrm{P}_{\text {sed }}+\mathrm{P}_{\mathrm{g}}$ picks and $310 \mathrm{P}_{\mathrm{n}}$ picks determined for 13 shot points along the profile. To build the initial model, first a one-dimensional velocity curve was flattened and smoothed to provide the smallest RMS travel time misfit of the starting model. As the geological/geophysical cross section (Fig. 4) shows varying velocities and thickness of the sediments along the profile, next, the initial (2D) model was prepared by a linear interpolation between previously prepared one-dimensional curves modified in the upper part $(0-5 \mathrm{~km})$ and located at the model edges, to reflect these velocity/depth variations $(\sim 3.5-$ $5.5 \mathrm{~km} / \mathrm{s}$ in the left edge and $5.5-5.9 \mathrm{~km} / \mathrm{s}$ in the right, at $0-3 \mathrm{~km}$ depth) and to build a more realistic initial model. This initial model provided an acceptable RMS of $0.22 \mathrm{~s}\left(\chi^{2}=5\right)$ at the first iteration and ensured the successful determination of the final one.

The final model was calculated in 9 iterations, using initial regularization strength (lambda 0 ) of 30 , and vertical to horizontal model roughness $(S z)$ value 0.2 . The $\chi^{2}$ for final model was 1.3 (RMS $d t=0.11 \mathrm{~s}$ ). The abilities of this modelling package is summarized in Table 1.

In Fig. 7a, the diagram of residuals show few positive residuals (mainly in the area with substantial thickness of the sediments - distances $0-250 \mathrm{~km}$ along the profile) reaching $0.5-0.7 \mathrm{~s}$, more than the overall RMS residual. It means that modeled velocities in the uppermost part of the sedimentary layer are too high compared to real values. It is most likely due to a relatively large vertical spacing of the inverse grid $(2 \mathrm{~km})$ and regularization (smoothing) applied to the model, which prevented the precise recovering of low $(<5 \mathrm{~km} / \mathrm{s})$ velocities in a thin $(<2 \mathrm{~km})$ layer of subsurface sediments.

Tomographic inversion, using a single velocity grid and smoothing, will image existing velocity discontinuities as zones of an elevated velocity gradient, rather than as sharp velocity contrasts. This is also the case of the Moho discontinuity in the presented model. In order to approximately locate the Moho, we assume that the gradient zone at the lower crustal/upper man-

Fig. 7. The P-wave velocity model obtained from tomographic inversion of the first arrivals ( $\mathrm{P}_{\mathrm{g}}$ and $\mathrm{P}_{\mathrm{n}}$ phases) using the FAST package: (a) Travel time residuals (red $\mathrm{P}_{\mathrm{g}}$ phase, blue $-\mathrm{P}_{\mathrm{n}}$ phase); (b) Observed (green) and calculated (red) travel times; (c) $V p$ velocity model based on the $\mathrm{P}_{\mathrm{g}}$ phase; (d) $V p$ velocity model based on the $\mathrm{P}_{\mathrm{g}}$ and $\mathrm{P}_{\mathrm{n}}$ phases. The $7.5 \mathrm{~km} / \mathrm{s}$ velocity isoline, considered to approximately represent the location of the Moho discontinuity in a model with smooth velocity distribution, is marked by a blue dotted line; (e) Ray density. 
tle depth in the model represents a smoothed image of the velocity increase from typical lower crustal $(<7 \mathrm{~km} / \mathrm{s})$ to typical upper mantle $(>8 \mathrm{~km} / \mathrm{s})$ values. Thus we tentatively locate the Moho boundary at the $7.5 \mathrm{~km} / \mathrm{s}$ velocity isoline, representing the average of these values (Fig. 6), not at the isoline of velocity expected for the uppermost mantle $(8.15-8.4 \mathrm{~km} / \mathrm{s})$.

\subsection{Joint refraction and reflection travel time tomography with JIVE3D}

The tomographic code JIVE3D was used to test the ability of inversion in case of a complex Moho shape. Methods based just on first arrivals (e.g., Hole 1992, Zelt and Barton 1998) use a part of the available travel time data only, without other (reflected) arrivals. The JIVE3D 3D tomographic software package (Hobro 1999, Hobro et al. 2003) is a suitable solution as it allows for the use of later refracted phases as well as reflected arrivals, apart from refracted first arrivals, to build a layered model.

The JIVE3D code is based on the regularized least squares inversion approach. The model is defined as a stack of layers separated by interfaces which can represent velocity discontinuities. Both refracted and reflected arrivals can be used. Models are parameterized by regular grids of velocity and depth nodes, from which the interface surfaces and velocity fields for individual layers are B-spline interpolated. The ray theory and ray perturbation method are used for travel time calculations. The inversion is performed using the iterative regularized least-squares method.

The JIVE3D package allows every layer and interface to be modelled separately or jointly. The usual approach is to model the upper parts of the crust first, and then successively resolve the deeper layers. The shallower, previously modelled layers can be fixed during the following inversion steps, in order to focus the algorithm on the deeper layer only. This reduces the number of model parameters and stabilizes the inversion procedure. Several runs of inversion (loops) with different regularization strengths are iteratively calculated. Thus, initially, a smooth solution is obtained and subsequently, the smoothness of the solution is gradually decreased in order to recover the smaller-scale details of the structure. Based on initial tests, appropriate regularization strengths (according to the terminology of Hobro (1999) and Hobro et al. (2003)) and a number of iterations in each loop (inversion run) were determined. The output model from one step is used as an input model for the next step of the inversion. Calculations are usually stopped when the value of $\chi^{2}$ stabilizes. The $1 \mathrm{D}$ initial input model was defined based on the 2D model from Starostenko et al. (2013) and some inversion tests. The code allows taking the surface topography into account. However, in this case a constant elevation $(0 \mathrm{~m}$ a.s.l.) of sources and receivers was assumed in the model. The grids cell size was defined as $5 \times 0.5 \mathrm{~km}$ 
for the crust and $10 \times 0.5 \mathrm{~km}$ for the upper mantle, node spacing for the Moho interface was set to $5 \mathrm{~km}$.

The sequence of modelling consisted of the following steps. First, refracted waves in the crust $\left(\mathrm{P}_{\text {sed }}, \mathrm{P}_{\mathrm{g}}, \mathrm{P}_{\text {ov }}\right)$ were modelled. $\mathrm{P}_{\text {sed }}$ branches were incorporated into the crustal layer. Modelling of a separate sedimentary layer increased the calculation time about twice, because of the relatively low density of rays compared to the vertical size of the layer. At the 6th loop with 6th iteration, the RMS value of $0.19 \mathrm{~s}\left(\chi^{2}=3.42\right)$ was reached and stabilized. The hit rate (percentage of receiver locations where a ray was traced successfully from the source) was $98 \%$. This model was used for the next step of the modelling as the starting model. In this step, a joint inversion of crustal velocities and Moho boundary based on waves refracted in the crust and reflected at the Moho interface was done $\left(\mathrm{P}_{\mathrm{sed}}, \mathrm{P}_{\mathrm{g}}, \mathrm{P}_{\mathrm{ov}}, \mathrm{P}_{\mathrm{M}} \mathrm{P}\right)$. We have limited Moho reflections to the first Moho arrivals. Unfortunately, JIVE3D software does not allow for the inversion of two phases from the same interface. At the 6th loop and 8th iteration the RMS of $0.18 \mathrm{~s}\left(\chi^{2}=2.66\right)$ was reached and stabilized. The hit rate was $94 \%$. This model was used as the starting model for the last step of the modelling. We used waves refracted in the upper mantle $\left(\mathrm{P}_{\mathrm{n}}\right)$ in this step of inversion. At the 4th loop and 12th iteration RMS of $0.16 \mathrm{~s}\left(\chi^{2}=2.42\right)$ was reached and stabilized. The hit rate was $89 \%$.

All the models are quite well determined. The tomographic model, ray density together with a comparison of experimental and calculated travel times and residuals are presented in Fig. 8. The residuals are largely limited to $\pm 0.15 \mathrm{~s}$. The abilities of this modelling package are summarized in Table 1 .

The best ray coverage is obtained in the upper crust down to $20 \mathrm{~km}$ depth (Fig. 8). The best ray coverage in the lower crust is obtained at distances of $140-225 \mathrm{~km}$ and $260-330 \mathrm{~km}$. The Moho boundary is better determined at distances of 140-400 km except for the segment in the vicinity of $210 \mathrm{~km}$. The best information about the upper mantle is obtained at distances of 150$370 \mathrm{~km}$, apart from the segment in the vicinity of $210 \mathrm{~km}$.

Comparing the tomographic inversion model to the forward ray tracing model described in Starostenko et al. (2013), we can see a similarity of the main features of the velocity field. Instead of some crustal discontinuities there are undulating velocity isolines at distances of about 100,230, and $400 \mathrm{~km}$. They coincide with a similar shape of the upper crustal layer in the model by Starostenko et al. (2013), but they reach the lower crust, probably due to smearing of the solution to the lower crust, not constrained by refracted waves.

The Moho shape is similar to this modelled by Starostenko et al. (2013), but the amplitude of undulations is lower. The undulations of the crustal velocity field roughly follow the Moho shape. There is an area of lower mantle velocity in the vicinity of $220 \mathrm{~km}$ of the model, which could indicate that the 

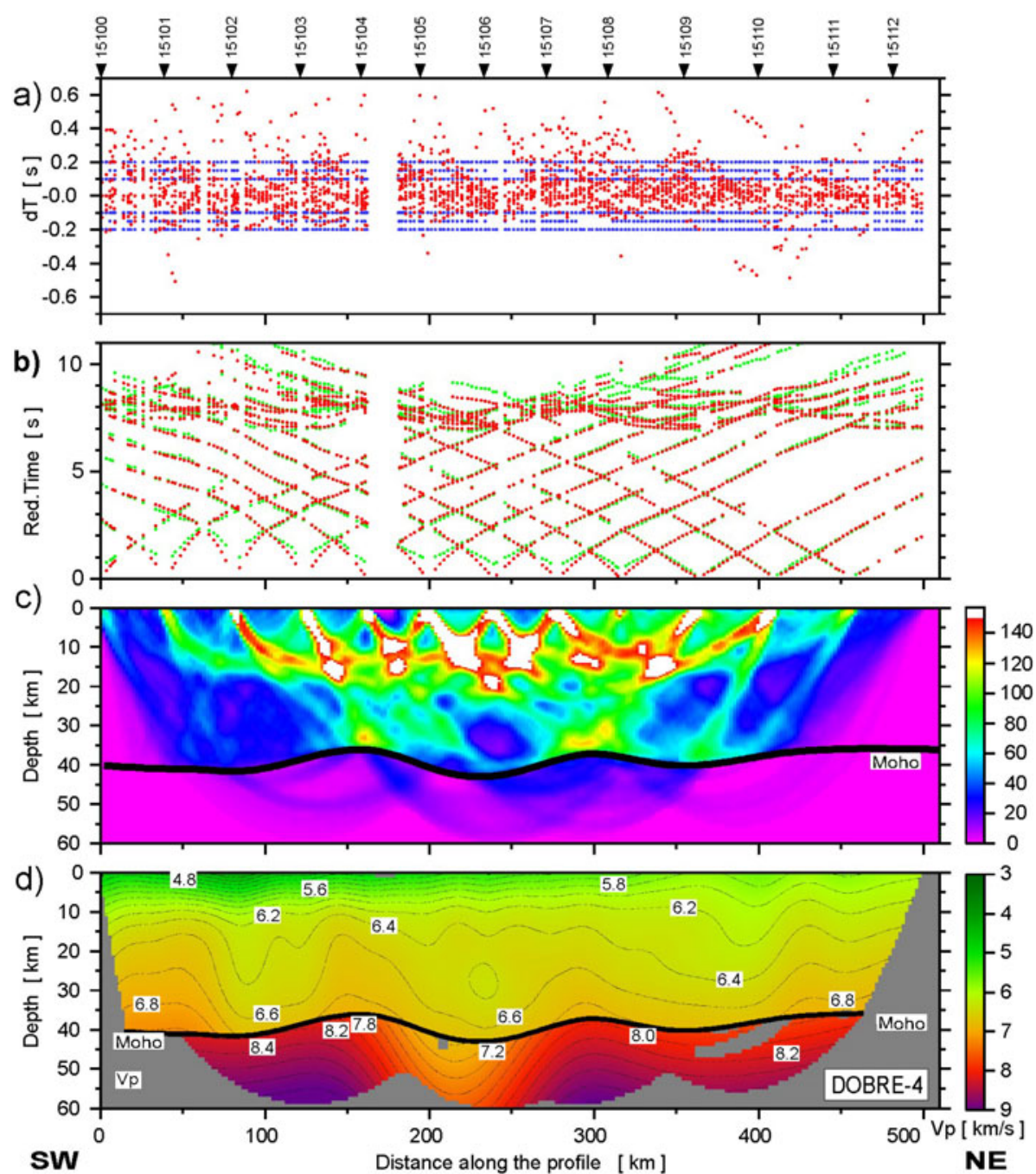

Fig. 8. The result of the JIVE3D modelling $\left(\mathrm{P}_{\text {sed }}, \mathrm{P}_{\mathrm{g}}, \mathrm{P}_{\mathrm{ov}}, \mathrm{P}_{\mathrm{M}} \mathrm{P}\right.$ and $\mathrm{P}_{\mathrm{n}}$ phases): (a) Residuals, blue dots - error limits (picking errors: $0.1 \mathrm{~s}$ for $\mathrm{P}_{\mathrm{g}}, 0.15 \mathrm{~s}$ for $\mathrm{P}_{\mathrm{n}}$, and $0.2 \mathrm{~s}$ for $\mathrm{P}_{\mathrm{M}} \mathrm{P}$ ), red dots - residuals; (b) Travel time fit, red dots - calculated travel times, green dots - experimental travel times; (c) Ray density. Colours represent the number of rays crossing a cell; (d) The final model. Model limited to the ray coverage area. Colours represent the P-wave velocity distribution, black thin lines - velocity isolines, black thick line - Moho seismic boundary.

inversion algorithm attempted to compensate for the insufficient deepening of the Moho at this distance. Thus, it could indicate that the true Moho undulation amplitude could be higher than that obtained by the modelling. Such a 
velocity undulation in the mantle was not observed by Starostenko et al. (2013) because the Moho interface modelled there is determined using all the Moho reflected branches, which is not the case for JIVE3D.

\subsection{Travel time inversion with RAYINVR}

Another variant of the solution was produced using the forward and inversion code RAYINVR (Zelt and Smith 1992). This code calculates ray paths, travel times and amplitudes of P- and S-waves using ray tracing by a numerical solution of the eikonal equation for $2 \mathrm{D}$ media with an inhomogeneous velocity distribution. The model can consist of layers separated by velocity discontinuities. The velocity is parameterized in each layer at irregularly located nodes and linearly interpolated between the nodes to define the velocity in each point of the model. Calculated travel times can be used as a basis for trial-and-error forward modelling or for regularized inversion to find the velocity distribution that fits the seismic data. The code allows for taking the surface topography into account. However, as the elevation in the study area did not exceed $160 \mathrm{~m}$, a constant elevation $(0 \mathrm{~m}$ a.s.1.) of sources and receivers was assumed in the model.

In this study, we attempted to use the regularized inversion with the DMPLSTSQR code, available within the RAYINVR package, in order to obtain a layered model that could be compared with results of the trial-anderror forward modelling. The model (Fig. 9) is composed of three layers sediments, consolidated crust, and uppermost mantle. The velocities in the sediments were obtained from previous geophysical data and from the SEIS83 model by simplifying the detailed and complex velocity distribution into one gradient layer. The velocity in the sedimentary layer has been kept constant during the inversion.

As the input data, the first arrivals, $\mathrm{P}_{\text {sed }}$ (refraction from the sediments with apparent velocity $<5.7 \mathrm{~km} / \mathrm{s}$ ) and $\mathrm{P}_{\mathrm{g}}$ (refraction from the consolidated crust with apparent velocity $\geq 5.7 \mathrm{~km} / \mathrm{s}$ ) were used to constrain the depth of the sediments/consolidated crust boundary and the velocity distribution in the consolidated crust. The reflected phases from the Moho discontinuity $\left(\mathrm{P}_{\mathrm{M}} \mathrm{P}\right)$ as well as sub-Moho refractions $\left(\mathrm{P}_{\mathrm{n}}\right)$ served for modelling the depth of the Moho and the velocity in the uppermost mantle. The initial, 1D model of the velocity in the consolidated crust was obtained by a one-dimensional inversion of the averaged curve of all observed $\mathrm{P}_{\mathrm{g}}$ phase travel times. The shape of the bottom boundary of the sediments and the distribution of the $V p$ velocity in the crust was modelled by an inversion of the travel times of the $\mathrm{P}_{\mathrm{g}}$ phase. After three iterations, the $\mathrm{P}_{\mathrm{g}}$ RMS travel time residual was $0.09 \mathrm{~s}$ $\left(\chi^{2}=0.8\right)$ (with 939 rays traced out of 1070 total travel times, $88 \%$ hit rate). The $\mathrm{P}_{\text {sed }}$ phase was not used for an inversion of the velocity distribution in 

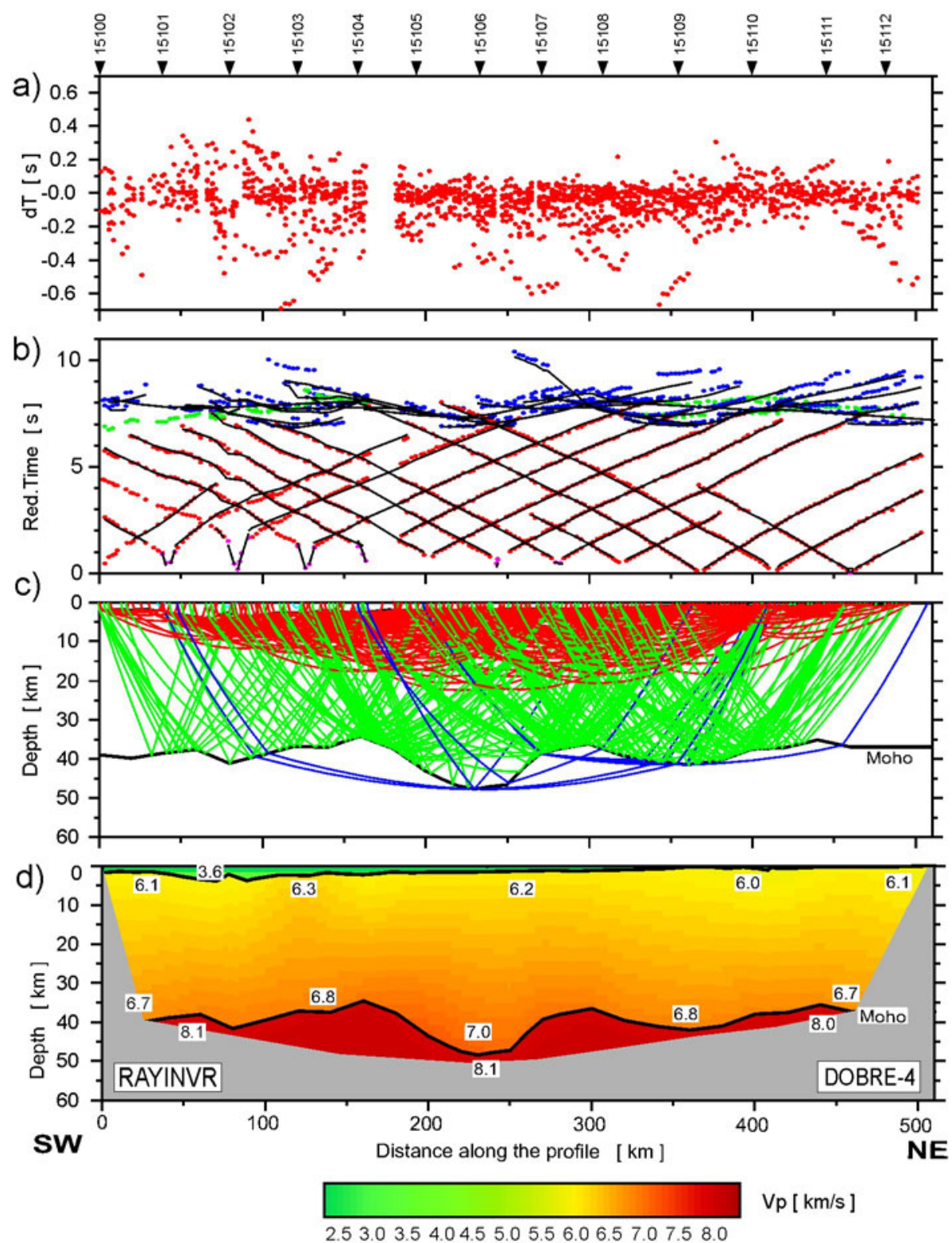

Fig. 9. P-wave velocity model obtained from inversion of the $\mathrm{P}_{\mathrm{g}}, \mathrm{P}_{\mathrm{M}} \mathrm{P}$, and $\mathrm{P}_{\mathrm{n}}$ phases using the RAYINVR package: (a) Residuals; (b) Travel time fit, black lines - calculated travel times, dots - observed travel times for $\mathrm{P}_{\mathrm{g}}(\mathrm{red}), \mathrm{P}_{\mathrm{M}} \mathrm{P}$ (blue), and $\mathrm{P}_{\mathrm{n}}$ (green) phase; (c) Ray diagram; (d) The final model limited to the ray coverage area. Colours represent the P-wave velocity distribution. 
the sediments, but $\mathrm{P}_{\text {sed }}$ RMS residuals calculated for $V p$ assumed (and kept fixed) in this layer are low enough $\left(0.11 \mathrm{~s}, \chi^{2}=1.2\right)$ to prove that the assumed velocity is realistic and does not bias the results from the deeper layers. The resulting crustal model shows an increasing thickness of the sedimentary layer - from $0 \mathrm{~km}$ in the north to $2-4 \mathrm{~km}$ in the south, consistently with the SEIS83 model and with tomographic models. In deeper parts, a slight lateral differentiation of the crustal velocity is observed, especially in the lower crust where high $(\sim 7.1 \mathrm{~km} / \mathrm{s})$ velocities are observed in the central part, compared to $6.7 \mathrm{~km} / \mathrm{s}$ in the north and south.

This crustal model served as a basis for modelling the Moho topography and the velocities in the uppermost mantle. For this, a simultaneous inversion of the $\mathrm{P}_{\mathrm{M}} \mathrm{P}$ and $\mathrm{P}_{\mathrm{n}}$ travel times was performed (keeping the crustal velocities constant). The $\mathrm{P}_{\mathrm{M}} \mathrm{P}$ phase in some seismic sections was observed as double (overlapping) phases with different apparent velocities (Figs. 3 and 6) (most likely resulting from abrupt changes of the Moho topography - reflections from Moho fragments with an opposite dip). This caused technical difficulties in using all available data for the inversion. The RAYINVR code is able to trace rays belonging to both overlapping phases in the forward step; however, during the inversion in locations where double arrivals of the phase are recorded, only the earliest calculated arrival time is taken for calculating the travel time residual, used subsequently in the inversion procedure to calculate the corrections/update of the velocity model. Therefore, when double $\mathrm{P}_{\mathrm{M}} \mathrm{P}$ phases were observed, only the fragments with first-arriving travel times were used (Fig. 10). The five steps of the inversion of the $\mathrm{P}_{M} \mathrm{P}$ and $\mathrm{P}_{n}$ phase resulted in a model with a RMS travel time residual of $0.13 \mathrm{~s}$ $\left(\chi^{2}=0.42\right)$ for the $\mathrm{P}_{\mathrm{M}} \mathrm{P}$ phase (with 550 rays traced for total 588 travel times, $93 \%$ hit rate) and $0.20 \mathrm{~s}\left(\chi^{2}=4\right)$ for the $\mathrm{P}_{\mathrm{n}}$ phase (with 41 rays traced for 160 observed travel times). The poor hit rate for the $\mathrm{P}_{\mathrm{n}}$ phase is due to "shadow zones" formed due to strong variations of the modelled Moho topography, which is inherent for most modelling methods based on ray approximation.

During this step, the crustal velocity was not included in the inversion. Nevertheless, as the velocities in this layer were interpolated between $V p$ values defined at nodes located along the layer boundaries, modification of the Moho interface resulted in a relocation of the corresponding velocity nodes and effectively affected the interpolated crustal velocity distribution. A modified crustal velocity field resulted in an increase of the $\mathrm{P}_{\mathrm{g}} \mathrm{RMS}$ residuals to $0.11 \mathrm{~s}\left(\chi^{2}=1.2\right)$. Therefore, 4 iterations of the inversion of the $\mathrm{P}_{\mathrm{g}}$ travel times were applied, which allowed for a decrease in the residuals to $0.09 \mathrm{~s}$ but increased the $\mathrm{P}_{\mathrm{M}} \mathrm{P}$ residuals to $0.16 \mathrm{~s}\left(\chi^{2}=0.64\right)$. Finally, an inversion of the $\mathrm{P}_{\mathrm{M}} \mathrm{P} / \mathrm{P}_{\mathrm{n}}$ travel times decreased the corresponding residuals to $0.13 / 0.20 \mathrm{~s}\left(\chi^{2}=0.42 / \chi^{2}=4\right)$, respectively. The value of the $\mathrm{P}_{\mathrm{g}}$ residuals for 


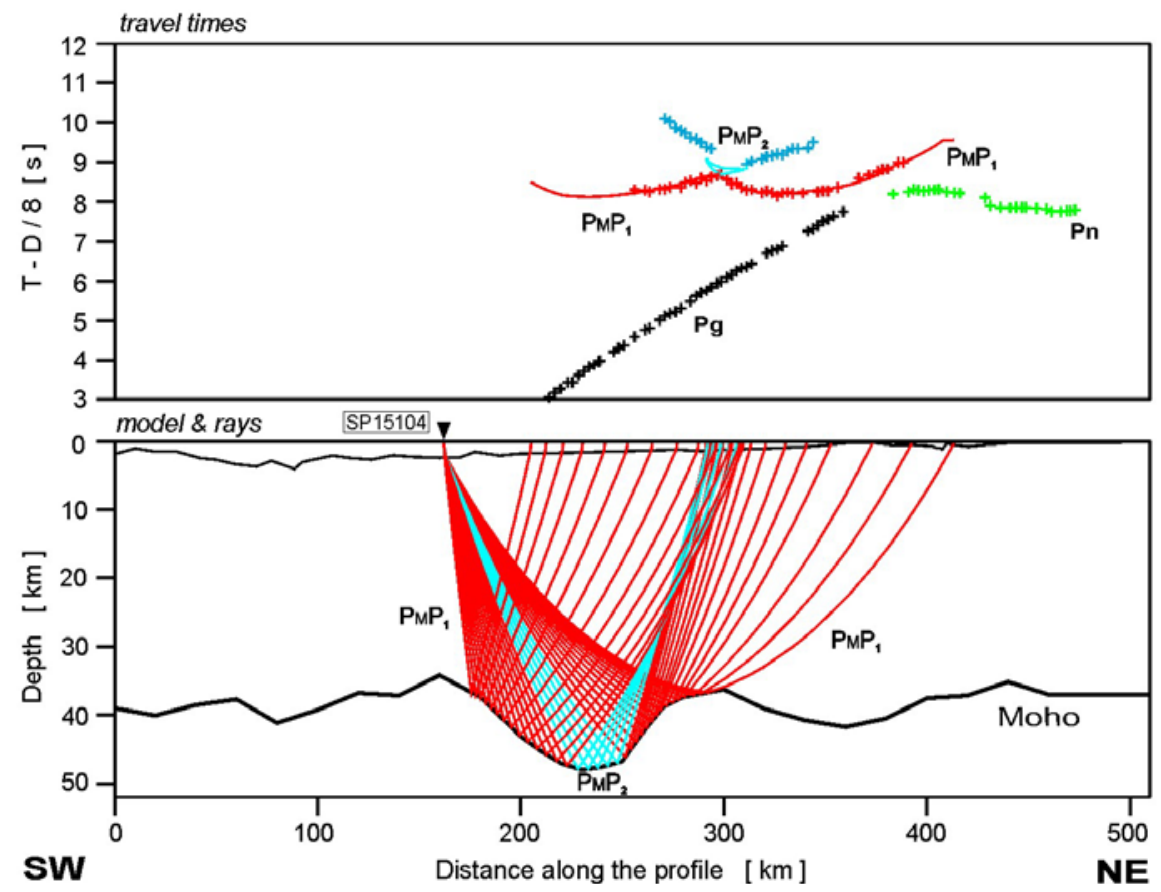

Fig. 10. Example of RAYINVR modelling of the overlapping $\mathrm{P}_{\mathrm{M}} \mathrm{P}$ phase as a reflection from opposite dipping slopes of a Moho trough. Top - observed (crosses) and calculated (lines) travel times. Bottom - a model with calculated rays reflected from Moho. Red - rays and travel times of the $\mathrm{P}_{\mathrm{M}} \mathrm{P}$ phase in earlier arrivals (used for inversion), Light blue - rays and travel times of $\mathrm{P}_{\mathrm{M}} \mathrm{P}$ in later arrivals (not used for inversion).

the final model was $0.1 \mathrm{~s}\left(\chi^{2}=1\right)$. The abilities of this modelling package are summarized in Table 1.

The resulting model shows the shape of the crust/mantle boundary very similar to the SEIS83 model, although with a smaller amplitude of the Moho trough at $\sim 300 \mathrm{~km}$ distance and with some differences at the edges of the model, not constrained by the data. This shows that using only first-arriving fragments of the overlapping $\mathrm{P}_{\mathrm{M}} \mathrm{P}$ phases for inversion gives a satisfactory result. However, it is likely that using all available travel times of the double $\mathrm{P}_{\mathrm{M}} \mathrm{P}$ phase would result in a more precise delineation of the Moho depth.

\section{DISCUSSION}

The unique Moho structure found along the DOBRE-4 profile provides valuable material to test different approaches of $2 \mathrm{D}$ wide-angle modelling. For these tests, SEIS83, FAST, JIVE3D and RAYINVR codes were used. 
The main objective of the comparison was to check to what extent the complex geometry of the Moho boundary will be recovered by tested software packages. The largest Moho depth change detected in previous study is from $32 \mathrm{~km}$ at a distance of $165 \mathrm{~km}$, down to $48 \mathrm{~km}$ at a distance of $250 \mathrm{~km}$ (Starostenko et al. 2013).

Although all the software packages allow the Earth's surface topography to be included, we did not take this into account, exception the SEIS83 model. The maximum terrain elevation is less than $160 \mathrm{~m}$, so the topography could be ignored.

The sedimentary sequences show a substantially lower velocity than the underlying basement; therefore, it is advisable to model them as a separate layer. This was possible in the case of the SEIS83, JIVE3D, and RAYINVR models. In the case of the FAST package, the model is parameterized as a single layer and therefore sediments are represented by a low velocity/high gradient area in the first few kilometers depth. In the JIVE3D model, after some tests, the sediments were also incorporated into the crustal layer due to a huge increase of the calculation time in case of a separate sedimentary layer. The time consumption necessary for the whole modelling procedure is also an important matter. The FAST package is the fastest way to have the first velocity model, although seismic boundaries cannot be represented by first order velocity discontinuities. Also, only refracted phases can be used.

The RAYINVR is also very fast in terms of computation time. However, the number of model parameters is typically orders of magnitude smaller than in the case of other tomographic codes. On the one hand, it allows for interactive, arbitrary (manual, if needed) selection of model parameters (boundary and velocity nodes) used for inversion, what makes it very flexible. On the other hand, sparse model parameterization results in a relatively low resolution. Moreover, selection of parameters for inversion requires interactive user input and testing of several variants of the solution, which makes the procedure time consuming. RAYINVR allows for using all refracted and reflected phases. The JIVE3D package is more time consuming but it can use $\mathrm{P}_{\mathrm{g}}, \mathrm{P}_{\mathrm{ov}}$ (refractions in later arrivals) and reflected phases.

The modelling with SEIS83 package is the most time-consuming. The code can use all refracted and reflected phases, including multiples or converted waves. The SEIS83 code solves the forward problem only (ray path and travel time calculation for a given velocity model). Unlike other discussed codes, it does not solve the inverse problem because it does not calculate the Frechet matrix to derive the model perturbations.

The calculations with SEIS83 are fairly fast, similarly to the RAYINVR code. However, manual, trial-and-error process of seeking the model fitting the data can be very time-consuming and usually takes large part of total modelling time. Such a procedure allows for better control of the modelling 
process, which is an advantage, but in the same time introduces some subjectivity into the final solution. Another advantage is that during modelling, it allows to modify the identification of picked phases. For example, problems with fitting some particular phase by a model fitting all the remaining data may indicate that such a phase actually originates as, e.g., side reflection or diffraction from some local structure, and thus should not be included in 2D modelling. This helps to eliminate artefacts that could be introduced by the modelling of some incorrectly interpreted phases, whose nature may not be obvious at first glance.

Forward modelling is a good tool for checking the phase identification, which is a key for obtaining a correct model. Also, it allows to build a detailed model using most of the information contained in the record sections.

Packages SEIS83 and RAYINVR allow to calculate synthetic seismograms and compare them with the experimental data.

Modelling of double (overlapping) phases in seismic sections, as observed in DOBRE-4 data, is problematic. SEIS83 can do it, RAYINVR can calculate rays and travel times for overlapping reflections in forward step, but in inverse step, if two arrivals of the same phase at the same sourcereceiver offset are calculated, only the earlier one is used for computing the residual and for inversion (see Fig. 10). JIVE3D cannot use overlapping reflections for inversion. To use whole branches of overlapping reflections for inversion, modifications of the RAYINVR or JIVE3D would be necessary.

2D tomographic codes are fast in terms of calculation time. However, finding a "realistic" solution requires several tests to find optimum parameters for inversion, including parameterization of the model (e.g., grid spacing, amount of regularization/smoothing, number of iterations) and the choice of the initial model. This can substantially increase the total modelling time. Nevertheless, inversion is still much faster than forward trial-anderror methods, as repetitive manual modification to fit the data for several shotpoints simultaneously is very complex and time-consuming. Moreover, the final result is to some extent subjective, as it depends on the experience, knowledge, and preferences of the interpreter. Also, this subjectivity makes it hard to quantitatively estimate the uncertainty or resolution of the model.

Figure 11 presents a comparison of the Moho shape derived by different approaches. All lines show a substantial variation of the Moho depth. The

Fig. 11. Comparison of the 2D seismic velocity models counted along the DOBRE-4 profile: (a) SEIS83 - the trial-and-error, ray tracing modelling; (b) FAST inversion; (c) JIVE3D - tomographic modelling; (d) RAYINVR inversion; (e) Comparison of the Moho boundaries obtained by using different approaches. Vertical exaggeration is $\sim 3.6: 1$ instead of $\sim 2.4: 1$, as used in other diagrams. 

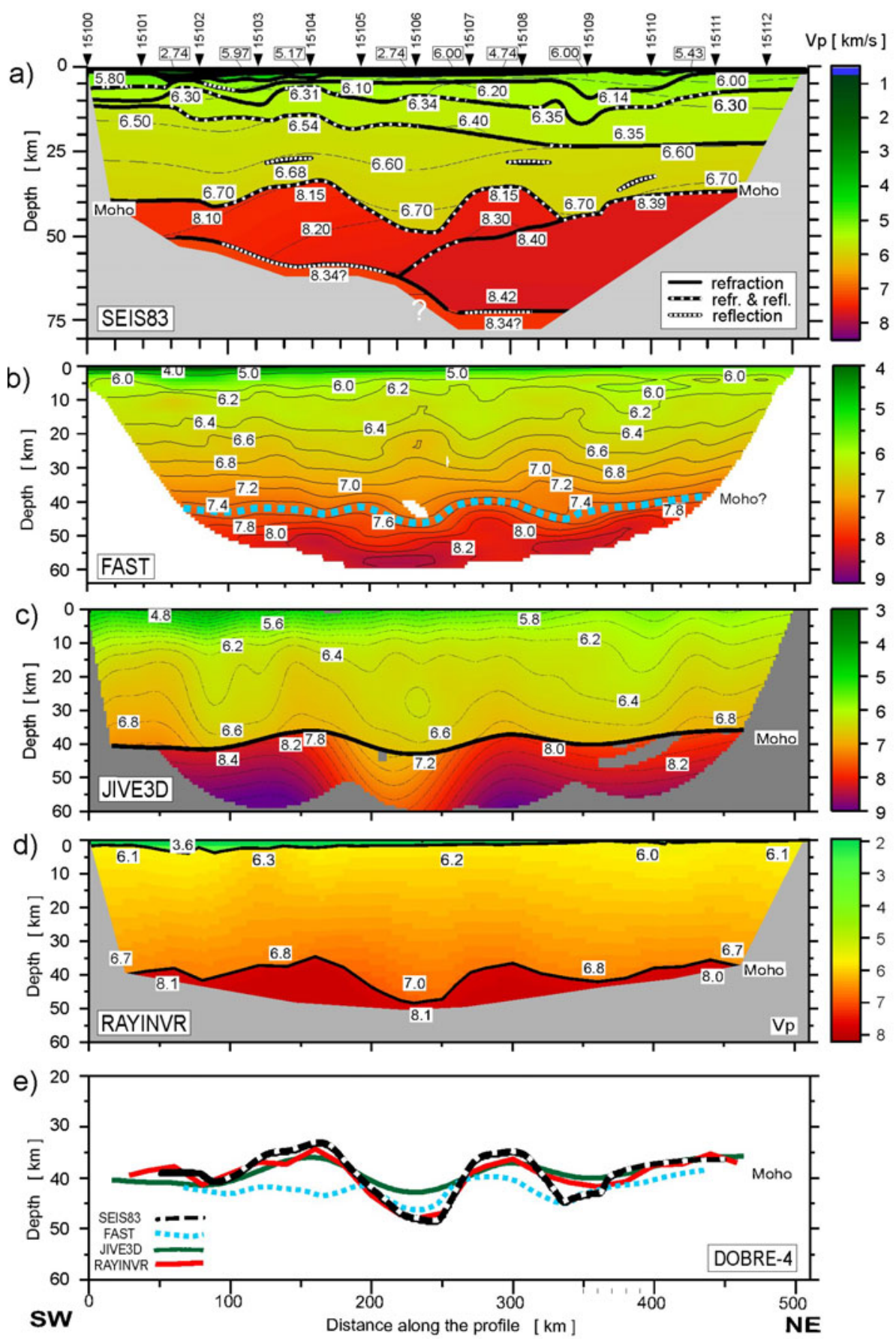
largest change is from $32 \mathrm{~km}$ at a distance of $165 \mathrm{~km}$ down to $48 \mathrm{~km}$ at a distance of $250 \mathrm{~km}$ in the SEIS 83 model. The line obtained by RAYINVR has a very similar shape (deviation from the SEIS 83 Moho $<3 \mathrm{~km}$ ), with the exception of a much less pronounced depression at $\mathrm{km} \mathrm{340,} \mathrm{where} \mathrm{the} \mathrm{Moho}$ depth is $\sim 40 \mathrm{~km}$ instead of $46 \mathrm{~km}$ in the SEIS83 model. The JIVE3D modelled the Moho depth similarly to SEIS83 and RAYINVR, but all depressions (km 250 and $\mathrm{km} \mathrm{340)}$ are smoothed (depth smaller by 7-8 km). Also the FAST line, which is based only on $\mathrm{P}_{\mathrm{g}}$ and $\mathrm{P}_{\mathrm{n}}$ phases, displays differences at a depth of the approximately determined Moho. In the points of maximum depth, the FAST Moho is deeper by 12 and $7 \mathrm{~km}$, respectively.

The Moho depth in the presented models fits with the $2.5-5 \mathrm{~km}$ accuracy the methods using $\mathrm{P}_{\mathrm{M}} \mathrm{P}$ phases. The biggest differences are observed at Moho uplifts and depressions. Better fit occurs for the Moho uplifts, with differences not exceeding $2.5 \mathrm{~km}$. The JIVE3D Moho is shallower in the depressions, with difference up to $5 \mathrm{~km}$. In the FAST model, the Moho boundary (approximately delineated along $7.5 \mathrm{~km} / \mathrm{s}$ velocity isoline) differs from other models by up to $10 \mathrm{~km}$ in depth. The conclusion is that using three methods (SEIS83, RAYINVR, and JIVE3D) to similar phases, we can obtain models with differences of $2.5-5 \mathrm{~km}$ in the Moho depth. Inversion of first arrivals only (FAST) gives much bigger differences, in our case $c a$. two times.

It is difficult to compare the quality and accuracy of the discussed models. The modelling procedure was different and different phases were used. For the FAST and RAYINVR, $\mathrm{P}_{\mathrm{g}}$ waves were used in one inversion step, while for the JIVE3D, $\mathrm{P}_{\mathrm{g}}$ (even $\mathrm{P}_{\text {ov }}$ ) and $\mathrm{P}_{\mathrm{M}} \mathrm{P}$ waves were modelled simultaneously. Table 1 presents seismic phases used by respective methods. For all the resulting models we can compare the fit of the solution to the data used for modelling (Figs. 5, 7, 8 and 9). It should be noted that this is only a measure of how far the synthetic data are from the observed data (travel time residual), not how far the final model is from the real structure (model uncertainty). Tomographic inversion methods, like FAST, RAYINVR, and JIVE3D, give a better fit, especially for $\mathrm{P}_{\mathrm{n}}$ waves. On the other hand, with these methods, it was not possible, or difficult, to use all the phases that were used for forward modelling with SEIS83 (Table 1).

In the case of a dataset with a complex wavefield, as presented here, some uncommon phases are hard to identify reliably at first glance, e.g., the overlapping Moho reflections modelled in this work. This poses a problem for any seismic inversion modelling, as it requires correct identification of the observed seismic phases (wave type and layer). In this case, the procedure of phase identification, ray tracing and inversion requires few "iterations", involving, if needed, re-identification of phase and subsequent modelling. For this, forward modelling is helpful, as it allows for verification of the correspondence between calculated rays/phases and observed phases. 
After a reliable identification confirmed by ray tracing, the data can be used for inversion modelling.

Another problem was encountered during modelling of the velocities in the upper mantle. For the DOBRE-4 profile, the topography of the Moho discontinuity produced the shadow zones for mantle phases due to the nature of the ray method. Therefore, for the modelling of the upper-mantle velocity distribution, two concurrent approaches were applied. The first one was based only on the ray theoretical algorithm, and the other approach used the full-waveform FD calculation to overcome the limitations of the ray method. This was described in the previous paper of Starostenko et al. (2013). Similarly, shadow zones for the $\mathrm{P}_{\mathrm{n}}$ were also formed during inversion modelling, which substantially decreased the hit rate for this phase. The effect of shadow zones, inherent for the ray-tracing algorithms used here, could be eliminated by application of the codes based on the graph (shortest path) method, described by Moser (1991) and successfully implemented for tomographic inversion by, amongst others, Korenaga et al. (2000) and Meléndez et al. (2015).

\section{CONCLUSIONS}

Modelling with all the codes tested showed substantial variability of the Moho depth along the DOBRE-4 profile. However, SEIS83 and RAYINVR packages seem to give the most coincident results. In the case of the FAST package, modelling of the Moho topography is problematic for two reasons. First, the model parameterization does not allow us to define velocity discontinuities which are represented in the model as zones of increased velocity gradient. Second - information about Moho is based on $\mathrm{P}_{\mathrm{n}}$ modelling only, as the reflected phases (most important for the modelling of Moho) are not used for inversion The JIVE3D model seems to be an intermediate model.

Not all the software packages can calculate double (overlapping) $\mathrm{P}_{\mathrm{M}} \mathrm{P}$ phases observed in seismic sections. This is possible with SEIS83; also RAYINVR could calculate rays and travel times for overlapping reflections in a forward step, but in the inverse step, if two arrivals of the same phase are calculated, only the earlier one is used for computing the residual and for inversion. JIVE3D cannot use overlapping reflections for inversion. Results of modelling of the DOBRE-4 dataset show that it would be interesting to introduce modifications to the RAYINVR or JIVE3D code to include all the travel times of overlapping reflected phases in inversion.

Acknowledgements. The public domain GMT software (Wessel and Smith 1991, 1998) was used to produce most of the figures. This work was partially supported within statutory activities No. 3841/E-41/S/2015 of the 
Ministry of Science and Higher Education of Poland and partially been financed from the funds of the Leading National Research Centre (KNOW) received by the Centre for Polar Studies for the period 2014-2018. The authors are grateful to two anonymous reviewers for helpful comments.

\section{References}

Červený, V., and I. Pšenčík (1984), SEIS83 - Numerical modeling of seismic wave fields in 2-D laterally varying layered structures by the ray method. In: E.R. Engdal (ed.), Documentation of Earthquake Algorithms, Rep. SE-35, World Data Center A for Solid Earth Geophysics, Boulder, USA, 36-40.

Grad, M., and A.A. Tripolsky (1995), Crustal structure from P and S seismic waves and petrological models of the Ukrainian shield, Tectonophysics 250, 89112.

Guterch, A., M. Grad, R. Materzok, and E. Perchuć (1986), Deep structure of the Earth's crust in the contact zone of the palaeozoic and precambrian platforms in Poland (Tornquist-Teisseyre zone), Tectonophysics 128, 251-279.

Hobro, J.W.D. (1999), Three-dimensional tomographic inversion of combined reflection and refraction seismic travel-time data, Ph.D. Thesis, Department of Earth Sciences, University of Cambridge, Cambridge.

Hobro, J.W.D., S.C. Singh, and T.A. Minshull (2003), Three-dimensional tomographic inversion of combined reflection and refraction seismic travel time data, Geophys. J. Int. 152, 1, 79-93.

Hole, J.A. (1992), Nonlinear high resolution three-dimensional seismic travel time tomography, J. Geophys. Res. 97, 6553-6562.

Komminaho, K. (1998), Software manual for programs MODEL and XRAYS: A graphical interface for SEIS83 program package, Rep. 20, University of Oulu, Dept. of Geophysics, 31 pp.

Korenaga, J., W.S. Holbrook, G.M. Kent, P.B. Kelemen, R.S. Detrick, H.-C. Larsen, J.R. Hopper, and T. Dahl-Jensen (2000), Crustal structure of the southeast Greenland margin from joint refraction and reflection seismic tomography, J. Geophys. Res. 105, 21591-21614.

Koulakov, I. (2009), LOTOS code for local earthquake tomographic inversion: benchmarks for testing tomographic algorithms, Bull. Seismol. Soc. Am. 99, 1, 194-214, DOI: 10.1785/0120080013.

Malinowski, M. (2013), Models of the Earth's crust from controlled-source seismology - where we stand and where we go? Acta Geophys. 61, 6, 1437-1456, DOI: $10.2478 / \mathrm{s} 11600-013-0156-7$.

Meléndez, A., J. Korenaga, V. Sallarès, A. Miniussi, and C.R. Ranero (2015), TOMO3D: 3-D joint refraction and reflection traveltime tomography paral- 
lel code for active-source seismic data-synthetic test, Geophys. J. Int. 203, 1, 158-174, DOI: $10.1093 / \mathrm{gji} / \mathrm{ggv} 292$.

Moser, T.J. (1991), Shortest path calculation of seismic rays, Geophysics 56, 1, 5967, DOI: 10.1190/1.1442958.

Rawlinson, N., and M. Urvoy (2006), Simultaneous inversion of active and passive source datasets for 3-D seismic structure with application to Tasmania, Geophys. Res. Lett. 33, L24313, DOI: 10.1029/2006GL028105.

Starostenko, V., T. Janik, D. Lysynchuk, P. Środa, W. Czuba, K. Kolomiyets, P. Aleksandrowski, O. Gintov, V. Omelchenko, K. Komminaho, A. Guterch, T. Tiira, D. Gryn, O. Legostaeva, H. Thybo, and A. Tolkunov (2013), Mesozoic(?) lithosphere-scale buckling of the East European Craton in southern Ukraine: DOBRE-4 deep seismic profile, Geophys. J. Int. 195, 2, 740-766, DOI: 10.1093/gji/ggt292.

Wessel, P., and W.H.F. Smith (1991), Free software helps map and display data, EOS Trans. 72, 41, 441-446, DOI: 10.1029/90EO00319.

Wessel, P., and W.H.F. Smith (1998), New, improved version of the Generic Mapping Tools released, EOS Trans. 79, 47, 579, DOI: 10.1029/98EO00426.

Zelt, C.A. (1994), Software package ZPLOT, Bullard Laboratories, University of Cambridge, Cambridge.

Zelt, C.A. (1999), Modelling strategies and model assessment for wide-angle seismic traveltime data, Geophys. J. Int. 139, 183-204.

Zelt, C.A., and P.J. Barton (1998), 3D seismic refraction tomography: a comparison of two methods applied to data from the Faeroe Basin, J. Geophys. Res. 103, 7.187-7.210.

Zelt, C.A., and R.B. Smith (1992), Seismic traveltime inversion for 2D crustal velocity structure, Geophys. J. Int. 108, 1, 16-34.

Received 15 February 2016

Received in revised form 1 July 2016

Accepted 23 August 2016 